\title{
Modeling Particle Deposition in the Pig Respiratory tract
}

3

${ }^{1}$ Applied Research Associates, Inc. 8537 Six Forks Road, Suite 600

Raleigh, NC 27615-2963

${ }^{2}$ Fred J. Miller \& Associates LLC

911 Queensferry Road

Cary, NC 27511-6422

${ }^{3}$ Applied Research Associates, Inc. 801 North Quincy Street, Suite 700

Arlington, VA 22203

${ }^{4}$ Pacific Northwest National Laboratory 902 Battelle Blvd.

Richland, Washington 99352

${ }^{5}$ Office of Naval Research

Arlington, VA 22217

Address for Correspondence: Bahman Asgharian, Applied Research Associates, 8537 Six Forks Road, Suite 600, Raleigh, NC 27615-2963

919-467-3194

basgharian@ara.com

KEY WORDS: Pig, lung geometry, morphometric variables, particles, deposition modeling

RUNNING HEAD: Pig lung deposition model 
1. ABSTRACT

Despite increasing use of pigs as surrogates for humans in inhalation studies, measurements of particle deposition in the lungs of pigs are lacking. No comprehensive models are available for deposition of inhaled particles in the lungs of pigs to bridge the gap between exposure and biological response. In this study, a mathematical model was developed for the deposition of particles in the respiratory tract of pigs. Semi-empirical equations were developed to relate particle deposition efficiency in the pig nasal passages to non-dimensional parameters for diffusion and impaction deposition. The conducting airway tree of pigs was reconstructed from scanned images and other morphometric data in the literature. The pulmonary airway region was reconstructed assuming geometric similarities between humans and pigs due to a lack of information available on the pulmonary airways of pigs. The tracheobronchial and alveolar trees were combined to obtain a limited-monopodial lung geometry for pigs. A lung ventilation model was developed in this geometry based on lung compliance, airway resistance, and airflow inertance using breathing parameters from the literature. The lung deposition model was constructed based on models for lung ventilation, particle transport, and deposition in the asymmetric (monopodial) lung structure to predict particle deposition in the lungs of pigs. Model predictions indicated that the largest airflow and particle deposition occurred in the basal (diaphragmatic) lobes, which possessed the largest airway dimensions and volumes. The predicted site of deposition was related to particle size with larger particles depositing proximally and smaller particles depositing distally. There was limited penetration of coarse particles into the alveolar region because most of these particles were removed from inhaled air in the nasal and tracheobronchial regions. The deposition model developed in this study is a powerful tool to relate exposure environment to biological response and assess the dose of the delivered particles to the lungs.

65 


\section{INTRODUCTION}

Pigs have been exposed to gases and particles by inhalation to study various respiratory responses such as pulmonary inflammation, improvement of impaired lungs in response to nitric oxide delivery, and deleterious effects of inhaled dust and endotoxins (e.g., Goebel et al., 2008; Herpin et al., 2015; Putensen et al., 1995; Urbain et al., 1999). Despite increased interest in using pigs as surrogates for humans in inhalation studies, measurements on particle deposition and gas uptake in the lungs of pigs are scarce. This information is crucial in relating the deposited dose to biological outcomes. The exposure-dose relationship is important for risk assessment from exposure to airborne materials and pharmaceutical drug delivery to elicit the targeted response.

Knowledge of particle deposition in different regions of the pig respiratory tract helps with the design of inhalation studies to target regions for studying biological endpoints of interest. Particle deposition modeling is a valuable asset, in the absence of measurements, to allow predictions of local and regional deposition of particles of various sizes under different exposure and breathing scenarios. However, there is not a complete model of the respiratory tract geometry of pigs, information on nasal and lung airways, nor information on physiological parameters to develop a comprehensive deposition model. Consequently, to date, there exists no model for inhalation of airborne materials into the lungs of pigs. While modeling the deposition of particles in the lungs of pigs is similar to those of other species, there are distinct differences in geometric structure, minute ventilation, and breathing rates, which must be taken into consideration. In particular, the respiratory tract geometry of many large animals such as sheep and pigs exhibit a monopodial branching structure, which cannot be represented accurately by a symmetric lung structure. In addition, calculations of airflow distribution in these lung geometries differ significantly from that in symmetric lung geometries such as humans (e.g., Asgharian et al., 2001).

In this study, airflow and particle deposition computations were conducted in the nasal passages of a pig reconstructed from scanned images to develop semi-empirical relationships for particle deposition by the mechanisms of Brownian diffusion and inertial impaction. In addition, geometric information was collected on airway lung parameters to construct an anatomically accurate lung geometry for pigs. Furthermore, physiologically realistic ventilation models of inhalation were developed based on lung compliance, airway resistance, and airflow inertance. Finally, a deposition model was developed for pigs based on asymmetric lung structure and ventilation. The deposition model was then used to predict local and regional deposition of particles in the pig respiratory tract.

\section{MATERIALS AND METHODS}

The mathematical model to predict particle deposition in the pig respiratory tract after aerosol exposure follows that of other species. Infeasibility of a full 3D, fluid dynamics approach due to complexity of airway structure, multi-dimensionality of airways, large numbers of airways, and uncertainty regarding the initial and boundary conditions for airflow provides justification to apply simplifying yet realistic assumptions based on physical grounds for lung geometry and airflow and particle transport to reduce the governing transport equations to $\mathrm{OD}$ and $1 \mathrm{D}$. Lower resolution modeling allows predictions of particle deposition for the entire respiratory tract. Basic assumptions include cylindrical airway 
geometry, symmetric lung structure when detailed morphometric information was missing, fully developed airflow in all airways when the flow Reynolds number dropped below unity, and replacement of the boundary conditions at airway walls by a sink term in the transport equations to account for particle removal from the inhaled air. These assumptions enabled separate calculations of airflow distribution in the upper respiratory tract (URT), which extended from the tip of the nose to the beginning of the trachea, and lower respiratory tract (LRT). In addition, because particle-airflow interaction was negligible, modeling of lung ventilation and particle transport in the LRT could be pursued independently. Predictive modeling of particle deposition involved performing four serial steps: calculation of particle deposition in the URT, reconstruction of LRT structure and dimensions based on the assumptions mentioned previously, modeling lung ventilation in the LRT, and developing a mathematical model to predict particle deposition in airways of the LRT during a complete breathing cycle (inhalation, pause, and exhalation).

\subsection{Particle removal and deposition fraction calculations in the URT}

The URT passages may serve as a target site for inhaled materials that may then be transported to the brain via the olfactory bulb or to other organs through systemic absorption. In addition, URT airway passages filter out inhaled materials to prevent or reduce entry into the LRT. It is therefore essential to estimate URT deposition for accurate estimates of lung deposition. Assessment of the URT filtering capability can be achieved either experimentally or numerically. In this study, magnetic resonance (MR) images (2 mm resolution) were used to reconstruct the URT geometry of a sedated 27-kg Yucatan miniswine pig extending from the tip of the nose to the beginning of the trachea (Figure 1). The geometry reconstruction was performed using 3D Slicer, which is available at http://www.slicer.org (latest accession date 10/2014) (Fedorov et al., 2012). The URT of the pig was comprised of two separate long primary channels in the nasal cavity that joined together in the nasopharyngeal duct and continued to the larynx and the upper trachea. The sinuses were not included in the URT geometry. Although some of the airways in the dorsal ethmoid region were not well characterized due to poor scan resolution, the main nasal channel, nasopharynx, and laryngeal regions were accurately captured.

An unstructured tetrahedral mesh with prism boundary layer was developed for the URT model using ICEM-CFD ${ }^{\mathrm{TM}}$ (Ansys, Inc. Canonsburg, PA.). The steady-state airflow field in this geometry was computed during inhalation using the commercial software package

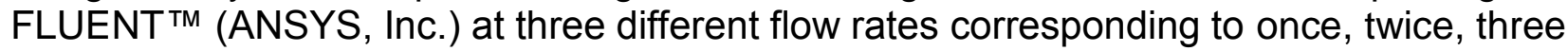
times the typical minute ventilation (MV) of a resting pig. The minute volume was estimated using the allometric formula from Bide et al. (2000). This corresponded to flow rates of 7 , 14 , and $21 \mathrm{~L} / \mathrm{min}$. The flow fields were used to calculate the trajectory of particles entering the URT geometry at equally spaced intervals on the nostril inlets of the pig URT. Deposition efficiency of inhaled particles ranging in size from $0.001 \mu \mathrm{m}$ to $20 \mu \mathrm{m}$ in diameter was calculated during inhalation using a Lagrangian particle tracking method, which included different external forces on particles due to gravity, impaction, and diffusion.

Particle deposition in the URT region occurs mostly by Brownian diffusion for nano-sized (ultrafine) particles and inertial impaction for coarse particles. Deposition fraction (efficiency) by Brownian diffusion depends on the inhalation flow rate, $\mathrm{q}\left(\mathrm{cm}^{3} / \mathrm{s}\right)$, and 
diffusion coefficient $D\left(\mathrm{~cm}^{2} / \mathrm{s}\right)$. Deposition efficiency by inertial impaction was related to the impaction parameter, $\rho d^{2} q\left(\mathrm{~g} \cdot \mu \mathrm{m}^{2} / \mathrm{s}\right)$, where $\rho$ is the particle mass density, $d$ is the particle diameter, and $q$ is the inhalation flow rate. A functional relationship for deposition efficiency $\left(\eta_{\mathrm{URT}}\right)$ by the deposition mechanisms of diffusion and impaction was selected with the following form.

$$
\eta_{\text {URT }}=1-\left(1-\eta_{\text {diff }}\right) \times\left(1-\eta_{\text {imp }}\right)
$$

where deposition efficiency by diffusion $\left(\eta_{\text {diff }}\right)$ and inertial impaction $\left(\eta_{\text {imp }}\right)$ were given by

Coefficients $\alpha, \beta, \gamma$, and $\delta$ were found by fitting numerically calculated deposition efficiencies to equations (1) - (3). Table I lists the values for parameters in equations (2) and (3). In contrast to the previous effort (Miller et al., 2014) in which separate numerical simulations and fits were made for particle deposition by Brownian diffusion and inertial impaction, the transport equations for the numerical simulations included both forces of diffusion and impaction and predicted deposition efficiency data were directly fitted to equation (1). As a result, more reliable predictions of deposition efficiency were obtained in the transition region where both Brownian diffusion and inertial impaction were of the same order of magnitude. Predicted particle deposition efficiency in the pig URT given by equations (1) (3) was compared with numerical calculations (Figure 2). There was an excellent agreement of the fit with numerical simulations in the diffusion and impaction dominated regions for all three inhalation flow rates. There were slight differences between predictions by numerical simulations and equations (1) - (3) in the transition region where deposition efficiencies by both mechanisms were small.

Equations (1) - (3) provide deposition efficiency of particles in the URT of a typical 27-kg pig. These equations were extended to animals of different body weights by assuming that the shape of the URT passages remained the same but airway dimensions changed with weight. Schmidt and Peclet numbers replaced $Q$ and $D$, respectively, and Stokes number replaced the impaction parameter in equations (2) and (3) to generalize relationships for deposition efficiencies by Brownian diffusion and inertial impaction. If nasal deposition efficiency of two animals of different weights (and nasal dimensions) are the same, their breathing parameters must vary proportionally for dynamic similarity to hold. The generalized equations of URT deposition efficiency by diffusion or impaction at two different weights were equated and simplified to obtain correction factors in equations (2) and (3) related to nasal volume to surface area ratio. Deposition efficiencies by diffusion and impaction at any weight of the animal were given by 


$$
\eta_{\mathrm{d}}=\left[\frac{1}{1+\alpha\left(\frac{\mathrm{V}_{0} / \mathrm{S}_{0}}{\mathrm{~V} / \mathrm{S}}\right) \mathrm{e}^{-\beta[\operatorname{Ln}(\mathrm{D})-\gamma]} \times \mathrm{q}^{\delta}}\right]^{1 / \alpha}
$$

$$
\eta_{\text {imp }}=\left[\frac{1}{1+\alpha\left(\frac{\mathrm{V}_{0} / \mathrm{S}_{0}}{\mathrm{~V} / \mathrm{S}}\right) \mathrm{e}^{-\beta\left[\operatorname{Ln}\left(\rho \mathrm{d}^{2} \mathrm{q}\right)-\gamma\right]}}\right]^{1 / \alpha}
$$

where $\mathrm{V}$ and $\mathrm{S}$ denote the URT volume and surface area, respectively, and subscript 0 denotes values at the reference weight of the pig $(27 \mathrm{~kg})$. Equation (1) is extended to pigs at all weights if equations (4) and (5) are used to calculate deposition efficiencies by diffusion and impaction. Values for nasal volume and surface area at a given weight are needed in order to calculate nasal deposition efficiency for that weight. Allometric equations developed across species for lung and breathing parameters (Miller et al., 2014) were used to calculate the nasal volume to surface area ratio at different weights of the animal.

\subsection{Lung geometry}

While the human lung airway structure resembles a symmetric branching tree, the lungs of rodents and a number of other large animals such as pigs and sheep exhibit monopodial branching patterns. The monopodial structure prevails particularly for large airways of the tracheobronchial tree beyond which smaller airways may be represented by symmetric structures in lieu of morphometric information and an abundance of airways per generation. A realistic geometry of the pig LRT must include key features of its structure. Hence, a lung geometry was constructed for the pig in which a monopodial structure of large airways transitioned to a symmetric structure with airway dimensions and orientations based on available data in the literature. The respiratory tract of the same $27 \mathrm{~kg}$ pig used in the URT analysis was imaged and reconstructed on the computer where acquired images of lung airway cross sections were assembled to create a three-dimensional surface mesh of the lung geometry (Figure 3A). The surface mesh was converted to airway volumes from which airway parameters (length, diameter, branching and gravity angles) and connectivity information were extracted (Figure 3B). Due to limitations in image resolution, only airway dimensions from airways with diameter of one millimeter and larger were captured. Altogether, the reconstructed airway tree contained 185 airways, of which 93 airways were exit or outlet branches. Figure 3 and Table II provide the reconstructed monopodial airway tree structure and airway parameters of the pig. The ID number in the table corresponded to the line number.

The TB airway tree given in Figure 3 and Table II provided the overall monopodial structure of the pig lung geometry. It served as the base on which the missing airways of the LRT were built. Maina and van Gils (2001) reported measurements of airway length and diameter of TB airways of the right lobe of $155 \mathrm{~kg}$ wild swine pigs at approximately $75 \%$ to $80 \%$ of total lung capacity (TLC). Measurements were made along selected pathways extending from large bronchi down to terminal bronchioles on 635 airways out of 
approximately 10,000 to 30,000 airways in the total TB region. The data set lacked key information such as branching structure and angles and was confined to measurements in the right lobe alone. Nonetheless, it contained sufficient details to allow construction of the missing portion of the TB tree as described below.

There was no physiologic information such as pig lung volumes (e.g., TLC or functional residual capacity, FRC, etc.) and breathing rates (tidal volume, breathing frequency, minute ventilation). We assumed that the left and right lobes of the animal lung contained the same number of airways and generations and the ratio of the right to left lobe lung volume was 55:45 (Haworth et al., 1981). Reported airway dimensions were used to construct a 14 generation symmetric tree for the pig TB region. Allometric equations developed across species for lung and breathing parameters (Miller et al., 2014) were used to calculate the TLC and alveolar volume of the $27-\mathrm{kg}$ pig. The difference of these volumes denoted the TB volume from which the volume of the monopodial tree was subtracted to find the volume of missing TB airways. A symmetric structure for the missing airways was adopted based on the fact that small airways are often oriented randomly (Weibel, 1963). The number of generations for the missing portion of the TB tree was found from the difference of generations between the symmetric and monopodial geometries and was found to be 3 . Dimensions of the missing airways of the TB subtree were rescaled to match the volume of the missing airways in the monopodial geometry.

A literature search revealed no information on pig airway orientation. In the absence of branching angle $(\theta)$ data specific to pigs, available data in a similar species (sheep) were used. Tawhai et al. (2004) reconstructed the sheep lung airway tree from CT scans and calculated average airway branching angles for different airway diameters. $A$ data fit $\left(R^{2}=\right.$ 0.89 ) with $\theta$ as an exponential function of airway diameter gave the following results.

$$
\theta=65.824 \times \mathrm{e}^{-1.3185 \times \mathrm{D}}
$$

The above equation was used to calculate branching angle $(\theta)$ for TB airways of the pig by using the pig airway diameter in each generation of the TB region.

No information was available for the gravity angle of pig airways. The gravity angle for the trachea is 90 degrees because the lungs lie horizontally in the chest cavity. In addition, because of the abundance of airways, the gravity angle for the terminal bronchioles and beyond was assumed to be random (i.e., $38.24^{\circ}$; obtained by integrating the angle an airway makes with the vertical plane over all possible direction degrees). Thus, the gravity angle was assumed to vary linearly from the trachea to the terminal bronchioles and remained at $38.24^{\circ}$ thereafter.

The symmetric 3-generation, TB subtree described above for the missing portion of the TB airways was attached to each of the 93 outlets of the monopodial tree to complete the TB structure. In addition, rescaling of the subtree was made before attachment to ensure an accurate account of the TB volume as predicted by the allometric equations (Miller et al., 2014).

Literature searches revealed no data on airway dimension measurements in the alveolar region of pigs. Thus, the alveolar geometry was constructed based on information in other 
species. Alveolar volume, surface area, and volume of ducts and number of alveoli were estimated for pigs from allometric relationships developed across species (Miller et al., 2014) using data from multiple sources (Gehr et al., 1981; Crapo et al., 1983; Mercer, et al., 1994; Stone et al., 1992; and Pinkerton et al., 1992). The alveolar geometry was constructed in two steps. First, the alveolar tree geometry was developed, and then the alveoli were distributed among the ducts. Due to the lack of information in pigs, the alveolar duct tree structure was assumed to resemble that of humans. Thus, a seven-generation, typical-path alveolar tree was assumed with one generation of very short respiratory bronchioles (Tyler and Julian, 1992) and six generations of fully alveolated alveolar ducts and sacs. Airway diameters were assumed to decrease with generation number in the same proportion as in humans. In addition, airway lengths were obtained based on having the same cumulative duct volume fraction in each airway generation of the alveolar region between humans and pigs. As for humans, an average 45 degrees branching angle and a random gravity angle (38.24 degrees) were used for each airway.

The volume of the alveoli was estimated to be $30 \%$ of the volume of the ducts. The pig alveoli were attached to the ducts to complete the alveolar geometry. The distribution of alveoli among different duct generation numbers of the pig was based on the fraction of duct surface alveolated in humans. The alveolar tree was attached to the terminal bronchioles of the TB tree to complete the pig lung geometry. As for the TB region, the alveolar tree was rescaled to ensure the total lung capacity matched that predicted from the allometric relationship for TLC. Table III provides the symmetric portion of the lung geometry, which included a three-generation TB subtree and a seven generation alveolar tree.

\subsection{Lung ventilation}

Accurate assessment of airflow distribution in the LRT is key in determining where inhaled particles travel and deposit. Airflow transport and distribution in the lung is the result of competing mechanisms of airway resistance, lung compliance, and airflow inertance. While these mechanisms are inter-dependent, they can be assumed to occur independently at normal breathing rates. Thus, the 3D governing (Navier-Stokes) equations for airflow can be linearized to model the dynamic system of airflow transport in the respiratory tract as a OD analog electric network. In this methodology, airway resistance is denoted by a resistor $(\mathrm{R})$, lung compliance by a capacitor $(\mathrm{C})$, and flow inertance by an inductor (L). If the entrance and exit of an airway are denoted by subscripts 0 and 1, momentum- and massbalance equations are written as given below for the parent branch denoted by subscript $p$ (Figure 4). calculate flow and pressure at the outlet of the trachea. 


$$
\left\{\begin{array}{l}
\mathrm{P}_{\mathrm{p}-1}=\mathrm{P}_{\mathrm{p}-0}-\mathrm{R}_{\mathrm{p}} \mathrm{q}_{\mathrm{p}-0}-\mathrm{L}_{\mathrm{p}} \frac{\mathrm{dq}_{\mathrm{p}-0}}{\mathrm{dt}} \\
\mathrm{q}_{\mathrm{p}-1}=\mathrm{q}_{\mathrm{p}-0}-\mathrm{C}_{\mathrm{p}} \frac{\mathrm{dP}_{\mathrm{p}-0}}{\mathrm{dt}}
\end{array}\right.
$$

321

322

323

324

325

326

327

328

329

330

The airflow at the outlet of the trachea splits and travels to each daughter branch. Since the splitting ratio is not known, equation (8) alone is insufficient to predict outflows into the daughter branches because the number of unknowns in equation (8) is more than the number of equations. A different approach is required to calculate flow and pressure variables at distal ends of lung airways.

Instead of traveling down the airway tree as implied above, flow variables can be first calculated for the most distal airways of the lung branching tree. The mass balance equation for the two most distal daughter branches of an airway bifurcation is given by

$$
\left\{\begin{array}{l}
\frac{\mathrm{dP}_{\mathrm{d}_{1}-0}}{\mathrm{dt}}=\frac{\mathrm{dP}_{\mathrm{p}-1}}{\mathrm{dt}}=\frac{\mathrm{q}_{\mathrm{d}_{1}-0}}{\mathrm{C}_{\mathrm{d}_{1}}} \\
\frac{\mathrm{dP}_{\mathrm{d}_{2}-0}}{\mathrm{dt}}=\frac{\mathrm{dP}_{\mathrm{p}-1}}{\mathrm{dt}}=\frac{\mathrm{q}_{\mathrm{d}_{2}-0}}{\mathrm{C}_{\mathrm{d}_{2}}}
\end{array}\right.
$$

where subscripts $p$ and d denote parent and daughter branches. It is noted that the flow rates vanish at the distal end of terminal daughter branches and pressure at the parent outlet is equal to that at each daughter inlet. In addition,

$$
\mathrm{q}_{\mathrm{d}_{1}-0}+\mathrm{q}_{\mathrm{d}_{2}-0}=\mathrm{q}_{\mathrm{p}-1}
$$

Combining the above two equations gives

$$
\left\{\begin{array}{l}
\mathrm{q}_{\mathrm{d}_{1}-0}=\frac{\mathrm{C}_{\mathrm{d}_{1}}}{\mathrm{C}_{\mathrm{d}_{1}}+\mathrm{C}_{\mathrm{d}_{2}}} \mathrm{q}_{\mathrm{p}-1} \\
\mathrm{q}_{\mathrm{d} 2-0}=\frac{\mathrm{C}_{\mathrm{d}_{2}}}{\mathrm{C}_{\mathrm{d}_{1}}+\mathrm{C}_{\mathrm{d}_{2}}} \mathrm{q}_{\mathrm{p}-1}
\end{array}\right.
$$

Airway compliance by definition depends on the inlet pressure of the airway. Hence, flow splitting in the most distal branches of the lung airway tree is proportional to the compliances of each daughter branch. It can be shown by network analogy that the two daughter branches can be replaced with one having a volume equal to the volume of two daughter branches, and a net compliance given by the sum of the compliances of each daughter branch.

$$
\mathrm{C}_{\mathrm{d}_{\text {net }}}=\mathrm{C}_{\mathrm{d}_{1}}+\mathrm{C}_{\mathrm{d}_{2}}
$$

Furthermore, by making the simplifying assumption of similar change in flow rates among the parent and daughter branches at an airway bifurcation, the net compliance for the most distal bifurcation consisting of the parent and two daughter branches can be found as 


$$
\frac{1}{\mathrm{C}_{(\mathrm{p}+\mathrm{d})_{\text {net }}}}=\frac{1}{\mathrm{C}_{\mathrm{p}}}+\frac{1}{\mathrm{C}_{\mathrm{d}_{\text {net }}}}
$$

where $\mathrm{C}_{\mathrm{d}_{\text {net }}}$ is the net compliance for the daughter branches and $\mathrm{C}_{(\mathrm{p}+\mathrm{d})_{\text {net }}}$ is the net compliance for the most distal bifurcation, which is made up of the parent and two daughter branches. In general, the net compliance for any airway of the lung is found by traversing up the subtree distal to the airway from the most distal daughter branches and calculating equations (12) and (13) cumulatively. Airflow distribution in the LRT is found by calculating the flow rate in each lung airway as described above.

Calculations of airflow rates and pressures during exhalation are very similar to those during inhalation. While airflow direction is reversed, the same governing equations (12 and 13) may be used to calculate airflow rates for all lung airways.

\subsection{Modeling particle transport and deposition}

As for airflow calculations, inhaled particles must be accounted for during a complete breathing cycle. The LRT is discretized into airways in which particle transport models are developed and solved to find regional and local deposition of inhaled particles. Discretization allows airway by airway calculations of airborne particle concentration and deposition in a concise and manageable manner but at the same time necessitates tracking of particles crossing different airways. Hence, models for particle mass balance must be developed within each airway of the LRT and at the bifurcations where particles may enter either of the two daughter branches. For a 1D formulation of particle transport and deposition, the convective diffusion equation for moving particles within an airway is given by

$$
\frac{\partial \mathrm{C}}{\partial \mathrm{t}}+\frac{\mathrm{q}}{\mathrm{A}} \frac{\partial \mathrm{C}}{\partial \mathrm{x}}=\mathrm{D} \frac{\partial^{2} \mathrm{C}}{\partial \mathrm{x}^{2}}-\frac{\eta \mathrm{q}}{\mathrm{V}} \mathrm{C}
$$

Where $C$ is the particle concentration, $t$ is the elapsed time, $q$ is the airflow rate through the airway, $\mathrm{A}$ is the airway cross-sectional area, $\mathrm{x}$ is the distance along the airway, $\mathrm{D}$ is the particle diffusion coefficient, $\eta$ is the overall deposition efficiency of particles in the airway by various mechanisms such as impaction, sedimentation, and Brownian diffusion, and $\mathrm{V}$ is the airway volume. Equation (14) was obtained assuming airways to be cylindrical with particle concentration and flow velocity to be uniform across airway cross sections. Thus, particle concentration varied only with time and lung depth. In addition, a sink (particle deposition) term ( $\eta \mathrm{q} / \mathrm{VC}$ ) was included in equation (14) in place of wall boundary conditions, which is absent in the 1D formulation.

The particle transport model represented by equation (14) may be applied to interior points of an airway but cannot be used at the boundary points and bifurcations where particles split between daughter branches. If an airway length is divided into $\mathrm{N}$ points at which particle concentrations are calculated, equation (14) is used to calculate particle concentrations at points 1 to $\mathrm{N}-1$ during inhalation and exhalation. A different approach is required for the calculations of concentration at distal ends of an airway as given in appendix A. During inhalation, the following expression was used to calculate particle 
400

401

402

403

404

405

406

407

408

409

410

concentration at the boundary point $\mathrm{N}$ at the distal end of the parent airway or point 0 at the proximal end of the daughter branches.

$$
\mathrm{C}_{0}=\frac{\mathrm{A}_{\mathrm{p}} \mathrm{D}-\Omega_{1}}{\mathrm{~A}_{\mathrm{p}} \mathrm{De} \mathrm{e}^{-\frac{\mathrm{q}_{\mathrm{p}}^{\prime} \Delta \mathrm{x}_{\mathrm{p}}}{\mathrm{A}_{\mathrm{p}} \mathrm{D}}}-\Omega_{1}-\Omega_{2}\left(1-\mathrm{e}^{-\frac{\mathrm{q}_{\mathrm{p}}^{\prime} \Delta \mathrm{x}_{\mathrm{p}}}{\mathrm{A}_{\mathrm{p}} \mathrm{D}}}\right) \frac{\mathrm{A}_{\mathrm{p}} \mathrm{D}}{\mathrm{q}_{\mathrm{p}}^{\prime}}} \mathrm{C}_{\mathrm{N}-1}
$$

Where $\Delta x$ is the discretized length segment, and subscripts $p$ and $d_{1}$ and $d_{2}$ denote parent and daughter branches 1 and 2, respectively.

$$
\Omega_{1}=A_{d_{1}} D \frac{\lambda_{1_{d_{1}}} e^{\lambda_{1_{d_{1}}} \Delta x_{\mathrm{d}_{1}}}-\lambda_{2_{\mathrm{d}_{1}}} e^{\lambda_{2_{\mathrm{d}_{1}} \Delta \mathrm{x}_{\mathrm{d}_{1}}}}}{\lambda_{1_{\mathrm{d}_{1}}}-\lambda_{2_{\mathrm{d}_{1}}}}-\frac{\mathrm{q}_{\mathrm{d}_{1}}\left(\mathrm{e}^{\lambda_{\mathrm{d}_{\mathrm{d}_{1}}} \Delta \mathrm{x}_{\mathrm{d}_{1}}}-\mathrm{e}^{\lambda_{2_{\mathrm{d}_{1}}} \Delta \mathrm{x}_{\mathrm{d}_{1}}}\right)}{\lambda_{1_{\mathrm{d}_{1}}}-\lambda_{2_{\mathrm{d}_{1}}}}
$$

$$
+\mathrm{A}_{\mathrm{d}_{2}} \mathrm{D} \frac{\lambda_{1_{\mathrm{d}_{2}}} \mathrm{e}^{\lambda_{\mathrm{d}_{2}} \Delta \mathrm{x}_{\mathrm{d}_{2}}}-\lambda_{2_{\mathrm{d}_{2}}} \mathrm{e}^{\lambda_{2_{\mathrm{d}_{2}} \Delta \mathrm{x}_{\mathrm{d}_{2}}}}}{\lambda_{1_{\mathrm{d}_{2}}}-\lambda_{2_{\mathrm{d}_{2}}}}-\frac{\mathrm{q}_{\mathrm{d}_{2}}^{\prime}\left(\mathrm{e}^{\lambda_{\mathrm{d}_{2}} \Delta \mathrm{x}_{\mathrm{d}_{2}}}-\mathrm{e}^{\lambda_{\mathrm{d}_{2}} \Delta \mathrm{x}_{\mathrm{d}_{2}}}\right)}{\lambda_{1_{\mathrm{d}_{2}}}-\lambda_{2_{\mathrm{d}_{2}}}}
$$

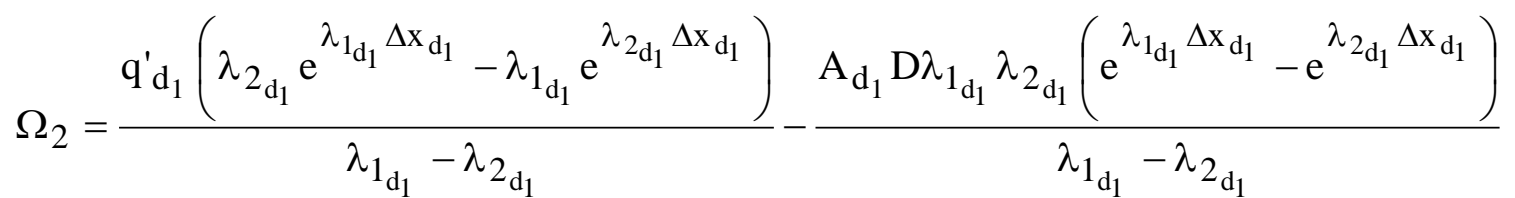

$$
\begin{aligned}
& \frac{\mathrm{q}_{\mathrm{d}_{2}}^{\prime}\left(\lambda_{2_{\mathrm{d}_{2}}} \mathrm{e}^{\lambda_{\mathrm{d}_{2}} \Delta \mathrm{x}_{\mathrm{d}_{2}}}-\lambda_{1_{\mathrm{d}_{2}}} \mathrm{e}^{\lambda_{2_{\mathrm{d}_{2}} \Delta} \mathrm{x}_{\mathrm{d}_{2}}}\right)}{\lambda_{1_{\mathrm{d}_{2}}}-\lambda_{2_{\mathrm{d}_{2}}}}-\frac{\mathrm{A}_{\mathrm{d}_{2}} \mathrm{D} \lambda_{1_{\mathrm{d}_{2}}} \lambda_{2_{\mathrm{d}_{2}}}\left(\mathrm{e}^{\lambda_{\mathrm{d}_{2}} \Delta \mathrm{x}_{\mathrm{d}_{2}}}-\mathrm{e}^{\lambda_{2_{\mathrm{d}_{2}} \Delta \mathrm{x}_{\mathrm{d}_{2}}}}\right)}{\lambda_{1_{\mathrm{d}_{2}}}-\lambda_{2_{\mathrm{d}_{2}}}} \\
& -\left(\mathrm{q}_{\mathrm{d}_{1}} \Delta \eta_{\mathrm{d}_{1}}+\mathrm{q}_{\mathrm{d}_{2}} \Delta \eta_{\mathrm{d}_{2}}\right)
\end{aligned}
$$$$
\lambda_{1_{\mathrm{d}_{1}}}=\frac{1}{2} \frac{\mathrm{q}_{\mathrm{d}_{1}}}{\mathrm{~A}_{\mathrm{d}_{1}} \mathrm{D}}\left(1+\sqrt{1+\frac{4 \Delta \eta_{\mathrm{d}_{1}}}{\Delta \mathrm{x}_{\mathrm{d}_{1}}} / \frac{\mathrm{q}_{\mathrm{d}_{1}}}{\mathrm{~A}_{\mathrm{d}_{1}} \mathrm{D}}}\right)
$$

$$
\lambda_{2_{\mathrm{d}_{1}}}=\frac{1}{2} \frac{\mathrm{q}_{\mathrm{d}_{1}}}{\mathrm{~A}_{\mathrm{d}_{1}} \mathrm{D}}\left(1-\sqrt{1+\frac{4 \Delta \eta_{\mathrm{d}_{1}}}{\Delta \mathrm{x}_{\mathrm{d}_{1}}} / \frac{\mathrm{q}_{\mathrm{d}_{1}}}{\mathrm{~A}_{\mathrm{d}_{1} \mathrm{D}}}}\right)
$$

Assuming diffusive fluxes to be small compared with convection fluxes at the bifurcations during exhalation, the following expression was used to calculate particle concentration at boundary point $\mathrm{N}$ during exhalation.

$$
\mathrm{C}_{\mathrm{N}}=\mathrm{C}_{\mathrm{N}-1}=\frac{\mathrm{q}_{\mathrm{d}_{1}}}{\mathrm{q}_{\mathrm{p}}} \mathrm{C}_{\mathrm{d}_{1}}+\frac{\mathrm{q}_{\mathrm{d}_{2}}}{\mathrm{q}_{\mathrm{p}}} \mathrm{C}_{\mathrm{d}_{2}}
$$


Detailed derivations of concentration calculations at the boundary points are given in Appendix A. Deposition fraction (DF) per airway of the LRT is obtained by integrating the mass flux of particles lost to the walls over airway volume and time.

$$
\mathrm{DF}=\iint \frac{\eta \cdot \mathrm{q} \cdot \mathrm{A}}{\mathrm{V}} \mathrm{Cdxdt}
$$

\section{RESULTS AND DISCUSSION}

Allometric relationships were obtained based on physiologic measurements of pigs and several other species as a function of body weight and included small and large animals (Miller et al. 2014). Table IV lists various equations derived for different lung and breathing parameters. These relationships were used to calculate lung and breathing parameters at different weights of the animal. The URT and LRT geometries of the pig were based on scanned images of a $27 \mathrm{~kg}$ pig. Thus, model predictions presented are for a $27 \mathrm{~kg}$ pig with limited monopodial lung geometry described above and physiologic parameters corresponding to a FRC of $999 \mathrm{~cm}^{3}$, URT volume of $137.5 \mathrm{~cm}^{3}$, and tidal volume of 449 $\mathrm{cm}^{3}$ as calculated from relationships in Table IV. A breathing period of 3.75 seconds was used (breathing frequency of $16 \mathrm{~min}^{-1}$ ) with equal inhalation and exhalation times and no pause.

The pig right lung lobe consists of right apical (RA), right middle (RM), right diaphragmatic $(\mathrm{RD})$, and intermediate/accessory (RI) lobes. Similarly, the left lobe consists of apical/left middle (LM) and left diaphragmatic (LD) lobes. Particle deposition in these lobes is directly related to the volume of particle-contained air reaching each lobe during a breathing cycle. The larger the volume, the greater the deposition may become. Thus, knowledge of lung ventilation provides insights into preferred sites of deposition in the lung, which could help with dose-response assessment and selection of lung locations for count and mass measurements of particle burdens. Airflow rate in each airway of the limited-monopodial lung tree was calculated from equations (11) - (13) starting from the most distal airways of the tree and traversing up as described in Lung Ventilation. Values for single airway compliances were provided by Ginzburg and Elad (1993). The flow rate into each lobe varied with time over a breathing cycle. An average flow rate entering each lung lobe was calculated and plotted in Figure 5. The airflow rates were fairly uniform among RA, RM, RI, and LM lobes. Significantly higher flow rates entered RD and LD lobes, which were about 8 to 11 fold higher than those going into other lobes. The highest flow rate was observed in the RD lobe. Flow rate in an airway depended on lung compliance (equation 11) and thus regional lung volume (Ginzburg and Elad, 1993). Hence, lung ventilation was proportional to regional distal volume. As a result, diaphragmatic lobes with the largest lobar volumes had the highest lobar inflows.

Equations (14) - (22) were solved numerically by finite differencing to calculate the concentration of inhaled particles in all lung airways. The lung is void of particles at the start of inhalation. Uniform inlet concentration during inhalation and zero diffusive flux of particles in the axial direction were assumed at the proximal end of the trachea during inhalation and exhalation, respectively. In addition, particle diffusive flux in the axial 
direction was assumed to vanish at the distal end walls of the most distal airways. Airflow rate and particle concentration varied with time and location in the lung during inhalation and exhalation despite having uniform inlet values at the trachea entrance. Figure 6 gives the normalized concentration (with respect to the trachea inlet) for $1-\mu \mathrm{m}$ particles along a selected path in the left and right diaphragmatic lobes of the pig lung during a single breathing cycle. Diaphragmatic lobes were selected for this plot due to having the highest inflows. Airway concentration in both lobes increased gradually with lung depth during inhalation as shown by the solid lines. Concentration curves showed a declining trend with generation number due to particle deposition in each generation as particles penetrated the LRT. At the end of inhalation, normalized concentration of particles was over $95 \%$ for the first 12 generations, which dropped fairly rapidly to zero between generations 12 and 14 in the RL lobe and 13 and 15 in the RD lobe, respectively. Particle concentration in LD and RD lobes decreased gradually during exhalation. Normalized concentration was below $20 \%$ throughout the lobes after about 3.6 seconds except for the first few generations. The lung was depleted of airborne particles at the end of the breathing cycle. Overall, there was more penetration of particles in the right lobe as compared to that in the left lobe, which could be attributed to the larger volume of the RD lobe.

A single lobe is often selected to measure the mass burden and biological response. The lobe with the highest burden is most appropriate for identifying the biological outcome if there is a dose-response relationship. In addition, knowledge of dose distribution among lung lobes alleviates the need to measure the burden in all lobes. The measured burden in one lobe can be adjusted by the dose distribution function to calculate burden in other lobes. To aid with lobe identification for experimental studies, the deposition fractions of particles in all 6 lobes of the pig lung were calculated for particle diameters of $0.01 \mu \mathrm{m}, 0.1$ $\mu \mathrm{m}, 1 \mu \mathrm{m}$, and $10 \mu \mathrm{m}$ using breathing parameters stated above (Figure 7). Deposition fractions were largest for $0.01 \mu \mathrm{m}$ and $10 \mu \mathrm{m}$ particles due to strong acting forces by diffusion and gravity and inertia, respectively. Deposition fractions were low for the intermediate particle size range where all deposition mechanisms were small. Despite minor differences, the distributions of deposition fraction among all particle sizes were similar. The lowest deposition fraction was observed in the right intermediate lobe while the right and left diaphragmatic lobes had the highest deposition fraction by about three to fourfold for all particle sizes. Interestingly, the deposition pattern among the lobes reflected the airflow distribution. The deposition fractions were similar among the remaining lobes. Thus, study of lung ventilation may serve as a guide for mass burden analysis in the pig lung lobes.

Nonuniformity of the deposited dose among various lobes of the pig lung has potential health impact with the lobe receiving the highest dose being most vulnerable to injury and adverse biological outcomes. The findings here also serve as a guide to the selection of the appropriate lobe to study dose and injury. The predicted results in pigs may not be generalized to other species as dose distribution may be species-specific. Thus, similar predictive models should be developed and used to assess lobar dose distribution in other species and study the health outcomes due to inhalation of airborne particles. 
The lung airway surfaces are covered with various cell types of unique sensitivities. The response of each cell type depends on the dose it receives. If the distribution on airway surfaces is known for each cell type, the cell dose can be related to biological response by calculating particle deposition as a function of lung depth. Particle deposition fractions at different generations of the LRT were calculated for the diaphragmatic lobes, which have the highest deposition of particles, and the entire LRT. Deposition patterns were similar between the two lobes but the magnitude of deposition was greater in the right diaphragmatic lobe. The results are presented in Figure 8. Left and right diaphragmatic lobes start from generations 3 and 4, respectively. There was a significant deposition of 10 $\mu \mathrm{m}$ particles in both left and right lobes by inertial impaction between generations 3 and 20 of the conducting airways. Deposition by sedimentation was significant for $1 \mu \mathrm{m}$ diameter particles, which seemed to have occurred in latter generations of the conducting tree and early generations of the alveolar region. The shape of the deposition fraction curves for 0.1 $\mu \mathrm{m}$ and $0.01-\mu \mathrm{m}$ particles was similar because deposition occurred mainly by Brownian diffusion for both sizes. Both lines peaked near the mid generations of the LRT. There was also a significant deposition of particles by impaction in common airways of the pig lung in generations 0 to 3 . Common airways are those airways that lead to lobes (trachea, primary bronchi, etc.), but are not located within a single lobe. Figure 8 indicated that particle deposition and, hence, cell dose depended on particle size and location in the LRT. Coarse particles tended to deposit in the proximal airways of the LRT. As particle size decreased the site for the bulk of deposition moved further into the lung. Ultrafine $(0.01 \mu \mathrm{m})$ particles deposition curves peaked near the end of TB region and beginning of the alveolar $(A)$ region.

Non-invasive measurements of burden during short and long term studies allow for assessment of particle deposition in the TB and A regions. Being able to make the same predictions aids with experimental design for particle size distribution and exposure concentration, which potentially can save time and cost by avoiding unnecessary experiments. Predicted regional deposition fractions of particles for lung and breathing parameters given in Table IV for a $27 \mathrm{~kg}$ pig are presented in Figure 9 for the cases of endotracheal and nasal breathing. Bypassing the nasal airway passages enables evaluation of deposition characteristics due to lung structure (Figure 9A). The overall pattern of deposition in each lung region was similar to that for other species. Particle deposition in the TB region occurred mainly by Brownian diffusion and inertial impaction in a similar fashion to that in the URT region (Figure 2). Ultrafine particles deposited in the latter airways of the TB tree by Brownian diffusion while significant inertial impaction occurred in throughout the TB region for coarse sized particles (Figure 8). Particle penetration into the alveolar region was limited for coarse sized particles because of particle filtering in the TB region. Coarse particles deposited in the alveolar region by gravitational settling. Ultrafine particle deposition by Brownian diffusion was greater in the alveolar deposition than that in the TB region.

There was very little lung deposition in the intermediate size range of $0.1 \mu \mathrm{m}$ to $1 \mu \mathrm{m}$ by nasal breathing because of the lack of strong external forces on airborne particles (Figure 9B). There was a significant deposition of particles in the URT for nano-sized (ultrafine) particles and coarse particles by Brownian diffusion and inertial impaction, respectively. Unlike other 
species, there was a notable filtering of particles in the intermediate size range $(0.1 \mu \mathrm{m}$ to 1 $\mu \mathrm{m})$, which indicated that diffusion and inertia were still significant in this size range. This may be due to the long narrow airway channels and nasopharyngeal duct in the pig nose to allow more time for deposition by diffusion. Because of the filtering effect of the URT, reduced penetration of particles into the thoracic region occurred. As a result, the deposition fraction curve in the TB region had a peak around $8 \mu \mathrm{m}$. Deposition fraction by inertial impaction was fairly significant in the URT and TB regions with a small fraction of particles being able to enter the A region. Overall deposition of particles in the A region was small for all particle sizes showing a peak around $5 \mu \mathrm{m}$.

\section{CONCLUDING REMARKS}

A mechanistic model was developed to predict the deposition of particles in the respiratory tract of pigs. Unique to the deposition model were a lung geometry consisting of a monopodial lung tree and a 3-generation symmetric TB subtree, and calculations of airflow and particle transport in this geometry. However, data gaps existed regarding physiological parameters and airway structure in the alveolar region, which were resolved by using interspecies relationships for breathing and lung parameters and assuming similarity between pig and human lung geometry in the alveolar region. Verification of model predictions was not possible due to the lack of deposition measurements. However, the mathematical model was based on the same principles and structure as models in other species for which verifications were made by comparing deposition predictions with measurements (e.g., Anjilvel and Asgharian, 1995; Asgharian et al., 2006, 2014; Miller et al., 2014). Model predictions gave similar deposition patterns across species. However, the magnitudes of deposition were quite different. The site of particle deposition in pigs seemed to be correlated with particle size with larger particles depositing proximally and smaller size particles depositing distally in the LRT. Higher resolution scans of the TB region would allow an improved lung model to be developed for pigs. 
6. ACKNOWLEDGEMENTS

576 This work was funded in part by the Office of Naval Research via contract N00014-12-C-

577 0624. Reconstruction of lung tracheobronchial tree was supported by a grant from the

578 National Heart, Lung, and Blood Institute (NHLBI R01 HL073598) of the National Institutes 579 of Health. 


\section{REFERENCES}

Anjilvel, S, and Asgharian, B (1995). A multiple path model of particle deposition in the rat lung Fundamental and Applied Toxicology 28:41-50.

Asgharian, B., Hofmann, W., and Bergmann, R. (2001). Particle deposition in a multiplepath model of human lung. Aerosol Science and Technology 34:332-339.

Asgharian, B., Price, O.T., and W. Hofmann, W. (2006). Prediction of Particle Deposition in the Human Lung Using Realistic Models of Lung Ventilation, Journal of Aerosol Science 37:1209-1221.

Asgharian, B., Price, O.T., Oldham, M., Chen, L.C., Saunders, E.L., Gordon, T., Mikheev, V.B., Minard, K.R., and Teeguarden, J.G. (2014). Computational modeling of manoscale and microscale particle deposition, retention and dosimetry in the mouse respiratory tract. Inhalation Toxicology 26(14):829-842.

Bide, R.W., Armour, S.J., and Yee, E. (2000). Allometric respiration/body mass data for animals to be used for estimates of inhalation toxicity to young adult humans. Journal of Applied Toxicology 20:273-290.

Crapo, JD, Young, SL, Fram, EK, Pinkerton, KE Barry, BE, and Crapo, RO. (1983). Morphometric characteristics of cells in the alveolar region of mammalian lungs. The American Review of Respiratory Disease 128:S42-S48.

Fedorov, A., Beichel, R., Kalpathy-Cramer, J., Finet, J., Fillion-Robin, J-C., Pujol, S., Bauer, C., Jennings, D., Fennessy, F., Sonka, M., Buatti, J., Aylward, S. R., Miller, J. V., Pieper, S., and Kikinis, R. (2012). 3D Slicer as an image computing platform for the quantitative imaging network. Magnetic Resonance Imaging 30(9):1323-1341.

Gehr, P, Mwanghi, DK, Amann, A, Maloiy, GMO, Taylor, R, and Weibel, ER. (1981). Design of the mammalian respiratory system $\mathrm{V}$. Scaling morphmetric pulmonary diffusing capacity to body mass: wild and domestic mammals. Respiratory Physiology 44:61-86.

Ginzburg, I. and Elad, D. (1993). Dynamic model of the bronchial tree. Journal of Biomedical Engineering 15:283-288.

Goebel U., Siepe ${ }_{2}$ M., Mecklenburg ${ }_{2}$ A., Stein P., Roesslein $_{2}$ M., Schwer ${ }_{1}$ C.I., Schmidt R., Doenst ${ }_{2}$ T., Geiger ${ }_{2}$ K.K. K., Pahl $_{2}$ H.L., Schlensak $_{2}$ C., and Loop, T. (2008). Carbon monoxide inhalation reduces pulmonary inflammatory response during cardiopulmonary bypass in pigs. Anesthesiology. 108(6):1025-1036.

Haworth, SG, McKenzie, SA, and Fitzpatrick, ML. (1981). Alveolar development after ligation of left pulmonary artery in newborn pig: clinical relevance to unilateral pulmonary artery. Thorax 36: 938-943. 
Herpin, P., Hulin, J.C., Dividich, J.Le, and Fillaut, M. ( 2015). Effect of oxygen inhalation at birth on the reduction of early postnatal mortality in pigs. Journal of Animal Science 79:5-10.

Maina, JN, and van Gils, P. (2001). Morphometric characterization of the airway and vascular systems of the lung of the domestic pig, Sus scrofa: comparison of the airway, arterial, and venous systems. Comparative Biochemistry and Physiology, Part A. 130:781-798.

Mercer, RR, Russell, ML, and Crapo, JD. (1994). Alveolar septal structure in different species. Journal of Applied Physiology 77:1060-1066.

Miller, F.J., Asgharian, B., Schroeter, J.D., Price, O.P., Corley, R.A., Einstein, D.R., Jacob, R.E., Cox, T.C., Kabilan, S., and Bentley, T. (2014). Respiratory tract lung geometry and dosimetry model for male Sprague-Dawley rats. Inhalation Toxicology 26: 524-544.

Pinkerton, KE, Gehr, P and Crapo, JD. (1992). Architecture and cellular composition of the air-blood barrier. In Comparative Biology of the Normal Lung. Ed. Parent, RA. CRC Press, Boco Raton.

Putensen $C^{1}$, Räsänen J, López FA. (1995). Improvement in VA/Q distributions during inhalation of nitric oxide in pigs with methacholine-induced bronchoconstriction. American Journal of Respiratory and Critical Care Medicine 151:116-22.

Stone, KC, Mercer, RR, Gehr, P, Stockstill, B, and Crapo, JD. (1992). Allometric relationships of cell numbers ad size in the mammalian lung. American Journal of Respiratory Cellular Molecular Biology 6:235-243.

Tawhai, MH, Hunter, P, Tschirren, J, Reunhardt, J, McLennan, G, and Hoffman, EA. (2004). CT-based geometry analysis and finite element models of the human and ovine bronchial tree. Journal of Applied Physiology 97:2310-2321.

Tyler, WS, and Julian, MD. (1992). Gross and subgross anatomy of lungs, pleura, connective tissue septa, distal airways, and structural units. In Comparative Biology of the Normal Lung. Ed. Parent, RA. CRC Press, Boco Raton, pp. 37-48.

Urbain $_{2}$ B., Mast, J., Beerens, D., N'Guyen, T.Q., Goddeeris, B., Ansay, M., and Gustin ${ }_{2}$ P. (1999). Effects of inhalation of dust and endotoxin on respiratory tracts of pigs. American Journal of Veterinary Research 60:1055-60.

Weibel, E.R. (1963). Morphometry of the Human Lung, Springer Verlag, Berlin,1963. 


\section{LIST OF TABLES}

Table I. Numerically calculated coefficients of equations (2) and (3).

Table II. Measured airway parameters of the monopodial tree captured from scanned images of a $27 \mathrm{~kg}$ pig. The most distal daughter airway branches were denoted by -1 . Airway ID system was included to show connectivity between parent and daughter branches.

Table III. Airway parameters of the symmetric subtree including a 3-generation TB subtree and a 7-generation A tree.

Table IV. Relationships of lung and breathing parameters with body weight of pigs. 


\section{FIGURE LEGENDS}

Figure 1: Lateral view of the pig URT CFD model. Three coronal cross-sections are shown in the main nasal cavity to demonstrate the airway structure.

Figure 2. Comparison of numerical calculations of particle deposition fractions in the pig nasal passages indicated by circular and square markers with predictions of semi-empirical equation (1) shown by solid lines.

Figure 3. Monopodial airway structure of large airways of the pig TB tree from scanned images: A. Reconstructed from scanned images, B. Airways converted to cylindrical tubes.

Figure 4. Electric network equivalence of an airway bifurcation where each airway is represented by a resistor, capacitor, and an inductor.

Figure 5. Average airflow rate in each lobe of the pig lung during inhalation.

Figure 6. Normalized concentration of 1 - $\mu$ m particles in the left and right diaphragmatic lobes via nasal breathing. The left and right diaphragmatic lobes start at generations 5 and 6 , respectively.

Figure 7. Deposition fraction of inhaled particles in different lobes of the pig lung via nasal breathing.

Figure 8. Deposition fraction per airway generation in the pig left and right diaphragmatic lobes and whole lung via nasal breathing.

Figure 9. Deposition fractions of particles in the upper respiratory tract (URT), tracheobronchial (TB), and alveolar (A) regions and entire respiratory tract of the pig lung. 
Table I. Numerically calculated coefficients of equations (2) and (3).

$\begin{array}{lll} & \text { Diffusion } & \text { Impaction } \\ \alpha & 10.6 & 6.02 \\ \beta & 2.79 & 8.61 \\ \gamma & -13.7 & 10.1 \\ \delta & 4.22 & 0.0\end{array}$


Table II. Measured airway parameters of the monopodial tree captured from scanned images of a $27 \mathrm{~kg}$ pig. The most distal daughter airway branches were denoted by -1 . Airway ID system was included to show connectivity between parent and daughter branches.

$\begin{array}{ccccccc}\text { ID } & \text { Length } & \text { Diameter } & \begin{array}{c}\text { Branching } \\ \text { angle }\end{array} & \begin{array}{c}\text { Gravity } \\ \text { angle }\end{array} & \begin{array}{c}\text { Daughter } \\ \text { degrees }\end{array} & \begin{array}{c}\text { Daughter } \\ \text { degrees }\end{array} \\ & \text { cm } & \text { cm } & \text { d } & \\ 1 & 15.05 & 1.84 & 0.0 & 106.2 & 2 & 3 \\ 2 & 2.50 & 0.67 & 72.4 & 101.9 & 4 & 6 \\ 3 & 4.28 & 1.80 & 8.7 & 103.2 & 7 & 5 \\ 4 & 2.45 & 0.43 & 58.9 & 123.3 & 9 & 10 \\ 5 & 2.51 & 1.25 & 38.8 & 93.2 & 8 & 12 \\ 6 & 0.84 & 0.44 & 36.3 & 65.9 & 13 & 11 \\ 7 & 3.64 & 1.18 & 49.7 & 92.2 & 14 & 15 \\ 8 & 3.06 & 0.37 & 66.3 & 38.8 & 16 & 18 \\ 9 & 1.35 & 0.21 & 60.8 & 74.4 & -1 & -1 \\ 10 & 0.54 & 0.41 & 14.2 & 136.2 & 21 & 19 \\ 11 & 0.83 & 0.40 & 18.0 & 51.1 & 17 & 20 \\ 12 & 0.84 & 1.21 & 14.6 & 101.6 & 22 & 26 \\ 13 & 1.69 & 0.20 & 95.4 & 97.6 & -1 & -1 \\ 14 & 1.52 & 0.58 & 45.1 & 67.3 & 25 & 24 \\ 15 & 1.71 & 1.07 & 38.9 & 115.7 & 23 & 27 \\ 16 & 1.52 & 0.27 & 71.7 & 108.7 & 35 & 29 \\ 17 & 1.23 & 0.21 & 44.7 & 91.0 & -1 & -1 \\ 18 & 1.35 & 0.37 & 12.7 & 49.6 & 39 & 38 \\ 19 & 1.61 & 0.28 & 29.7 & 117.8 & 30 & 33 \\ 20 & 4.37 & 0.27 & 71.5 & 30.5 & -1 & -1 \\ 21 & 1.12 & 0.26 & 28.7 & 144.5 & -1 & -1 \\ 22 & 2.80 & 0.44 & 54.7 & 62.5 & 36 & 32 \\ 23 & 2.03 & 0.40 & 48.9 & 148.9 & 37 & 31 \\ 24 & 1.34 & 0.46 & 50.9 & 72.0 & 28 & 42 \\ 25 & 1.57 & 0.46 & 69.5 & 112.5 & 40 & 41 \\ 26 & 0.98 & 1.10 & 25.4 & 116.9 & 43 & 44 \\ 27 & 1.43 & 0.99 & 31.9 & 83.7 & 34 & 45 \\ 28 & 0.54 & 0.28 & 53.8 & 111.8 & -1 & -1 \\ 29 & 1.09 & 0.27 & 38.6 & 95.4 & 49 & 50 \\ 30 & 0.36 & 0.17 & 64.2 & 73.3 & -1 & -1 \\ 31 & 1.24 & 0.32 & 40.1 & 128.7 & 46 & 52 \\ 32 & 2.20 & 0.39 & 3.0 & 60.0 & 47 & 48 \\ 33 & 1.13 & 0.22 & 27.6 & 140.7 & -1 & -1 \\ 34 & 2.24 & 0.53 & 41.2 & 69.1 & 54 & 55 \\ 35 & 1.34 & 0.22 & 21.9 & 125.5 & -1 & -1\end{array}$




$\begin{array}{lllllll}36 & 3.56 & 0.21 & 31.2 & 90.3 & -1 & -1 \\ 37 & 2.74 & 0.21 & 27.0 & 150.4 & -1 & -1 \\ 38 & 2.03 & 0.37 & 27.4 & 51.6 & 59 & 51 \\ 39 & 0.97 & 0.22 & 47.6 & 89.3 & -1 & -1 \\ 40 & 3.37 & 0.21 & 43.0 & 126.8 & -1 & -1 \\ 41 & 2.05 & 0.32 & 40.6 & 81.6 & 61 & 53 \\ 42 & 0.82 & 0.43 & 33.7 & 53.3 & 56 & 63 \\ 43 & 1.84 & 0.43 & 47.4 & 145.5 & 58 & 64 \\ 44 & 2.01 & 0.98 & 29.8 & 93.8 & 57 & 65 \\ 45 & 1.19 & 0.87 & 32.0 & 111.2 & 62 & 60 \\ 46 & 0.37 & 0.15 & 52.9 & 178.0 & -1 & -1 \\ 47 & 1.86 & 0.17 & 29.1 & 89.0 & -1 & -1 \\ 48 & 0.76 & 0.35 & 32.9 & 31.1 & 66 & 67 \\ 49 & 0.23 & 0.13 & 56.8 & 147.8 & -1 & -1 \\ 50 & 0.61 & 0.21 & 20.2 & 75.3 & -1 & -1 \\ 51 & 3.04 & 0.31 & 24.0 & 54.4 & 69 & 68 \\ 52 & 0.88 & 0.21 & 60.4 & 90.7 & -1 & -1 \\ 53 & 3.42 & 0.23 & 28.1 & 65.4 & -1 & -1 \\ 54 & 2.03 & 0.26 & 51.5 & 116.1 & 71 & 70 \\ 55 & 1.36 & 0.47 & 38.6 & 47.8 & 77 & 78 \\ 56 & 0.56 & 0.20 & 46.8 & 87.6 & -1 & -1 \\ 57 & 2.13 & 0.52 & 62.3 & 46.6 & 73 & 74 \\ 58 & 0.98 & 0.27 & 77.6 & 136.7 & -1 & -1 \\ 59 & 0.57 & 0.21 & 51.0 & 56.2 & -1 & -1 \\ 61 & 0.70 & 0.17 & 53.9 & 130.0 & -1 & -1 \\ 62 & 2.49 & 0.19 & 45.6 & 68.0 & -1 & -1 \\ 63 & 1.56 & 0.42 & 33.1 & 51.9 & 80 & 81 \\ 64 & 0.47 & 0.46 & 35.3 & 110.7 & 76 & 82 \\ 65 & 1.31 & 0.93 & 27.5 & 120.2 & 83 & 84 \\ 66 & 0.69 & 0.16 & 46.6 & 54.9 & -1 & -1 \\ 67 & 0.87 & 0.28 & 34.8 & 59.0 & 85 & 86 \\ 68 & 2.19 & 0.23 & 12.4 & 44.1 & -1 & -1 \\ 69 & 0.39 & 0.17 & 57.6 & 100.0 & -1 & -1 \\ 70 & 0.49 & 0.15 & 35.9 & 148.9 & -1 & -1 \\ 71 & 1.02 & 0.13 & 35.8 & 81.2 & -1 & -1 \\ 72 & 2.14 & 0.43 & 56.7 & 71.8 & 89 & 87 \\ 73 & 1.86 & 0.21 & 50.2 & 48.5 & -1 & -1 \\ 74 & 1.10 & 0.52 & 34.4 & 80.3 & 94 & 101 \\ 75 & 1.43 & 0.68 & 23.2 & 109.7 & 92 & 93 \\ 76 & 1.89 & 0.21 & 19.4 & 91.3 & -1 & -1 \\ 77 & 2.34 & 0.19 & 28.4 & 30.1 & -1 & -1 \\ 78 & 0.56 & 0.40 & 31.3 & 77.9 & 90 & 99 \\ 79 & 0.73 & 0.21 & 46.8 & 97.2 & -1 & -1 \\ & & & & & & \\ 53 & & & & & & \end{array}$




$\begin{array}{ccccccc}80 & 2.07 & 0.34 & 20.5 & 36.4 & 96 & 98 \\ 81 & 1.18 & 0.34 & 38.7 & 142.9 & 91 & 95 \\ 82 & 1.91 & 0.44 & 50.6 & 149.7 & 102 & 88 \\ 83 & 0.67 & 0.94 & 51.1 & 70.8 & 100 & 97 \\ 84 & 0.34 & 0.17 & 61.6 & 78.8 & -1 & -1 \\ 85 & 0.80 & 0.19 & 34.6 & 28.2 & 104 & 110 \\ 86 & 0.44 & 0.43 & 34.2 & 101.8 & 103 & 108 \\ 87 & 1.56 & 0.28 & 44.4 & 107.3 & -1 & -1 \\ 88 & 1.10 & 0.18 & 59.5 & 46.0 & -1 & -1 \\ 89 & 0.84 & 0.15 & 58.8 & 80.9 & -1 & -1 \\ 90 & 0.31 & 0.17 & 66.4 & 76.6 & -1 & -1 \\ 91 & 2.61 & 0.17 & 45.3 & 72.0 & -1 & -1 \\ 92 & 1.09 & 0.66 & 21.1 & 121.8 & 107 & 116 \\ 93 & 2.09 & 0.19 & 50.2 & 121.0 & 106 & 105 \\ 94 & 0.94 & 0.23 & 28.6 & 159.4 & -1 & -1 \\ 95 & 0.48 & 0.25 & 50.4 & 84.8 & -1 & -1 \\ 96 & 1.78 & 0.80 & 43.8 & 109.0 & 112 & 113 \\ 97 & 4.18 & 0.26 & 25.9 & 30.3 & -1 & -1 \\ 98 & 1.03 & 0.38 & 19.6 & 61.9 & 114 & 115 \\ 99 & 4.11 & 0.24 & 18.6 & 80.0 & -1 & -1 \\ 100 & 1.21 & 0.48 & 26.7 & 62.8 & 109 & 111 \\ 101 & 2.55 & 0.26 & 47.0 & 137.9 & -1 & -1 \\ 102 & 0.78 & 0.16 & 65.2 & 87.4 & -1 & -1 \\ 103 & 0.78 & 0.15 & 32.5 & 55.0 & -1 & -1 \\ 104 & 0.41 & 0.16 & 46.3 & 76.6 & -1 & -1 \\ 105 & 0.55 & 0.14 & 26.8 & 147.7 & -1 & -1 \\ 106 & 0.93 & 0.27 & 63.8 & 168.1 & 128 & 127 \\ 107 & 1.66 & 0.40 & 37.4 & 82.8 & 129 & 125 \\ 108 & 1.19 & 0.35 & 32.0 & 31.2 & 117 & 119 \\ 109 & 0.55 & 0.19 & 65.6 & 52.2 & -1 & -1 \\ 110 & 0.98 & 0.37 & 32.8 & 95.3 & 121 & 124 \\ 111 & 1.69 & 0.43 & 54.0 & 75.2 & 118 & 126 \\ 112 & 0.57 & 0.74 & 47.3 & 126.0 & 123 & 130 \\ 113 & 2.05 & 0.20 & 24.2 & 86.0 & -1 & -1 \\ 114 & 3.18 & 0.25 & 22.8 & 40.4 & -1 & -1 \\ 115 & 0.64 & 0.64 & 31.8 & 90.0 & 120 & 122 \\ 116 & 1.23 & 0.21 & 39.7 & 28.2 & -1 & -1 \\ 117 & 1.41 & 0.15 & 56.9 & 41.1 & -1 & -1 \\ 118 & 1.76 & 0.27 & 9.6 & 40.5 & 135 & 136 \\ 119 & 1.55 & 0.36 & 43.8 & 91.6 & 131 & 137 \\ 120 & 0.71 & 0.15 & 64.7 & 72.3 & -1 & -1 \\ 121 & 1.33 & 0.56 & 34.0 & 113.3 & 138 & 140 \\ 122 & 1.59 & 0.21 & 31.0 & 123.9 & -1 & -1 \\ & & & & & & \\ & & & & & & \end{array}$




$\begin{array}{lllllll}123 & 1.50 & 0.31 & 20.4 & 82.3 & 143 & 141 \\ 124 & 2.64 & 0.24 & 15.1 & 97.9 & 133 & 142 \\ 125 & 0.70 & 0.39 & 27.3 & 102.4 & 132 & 134 \\ 126 & 0.44 & 0.19 & 20.0 & 162.1 & -1 & -1 \\ 127 & 0.76 & 0.16 & 53.0 & 116.7 & -1 & -1 \\ 128 & 2.99 & 0.20 & 25.0 & 61.9 & -1 & -1 \\ 129 & 1.27 & 0.67 & 46.1 & 103.5 & 139 & 144 \\ 130 & 1.25 & 0.16 & 49.3 & 115.8 & -1 & -1 \\ 131 & 1.91 & 0.16 & 42.4 & 126.4 & -1 & -1 \\ 132 & 0.88 & 0.16 & 38.8 & 61.2 & -1 & -1 \\ 133 & 2.85 & 0.30 & 30.8 & 83.5 & 146 & 145 \\ 134 & 1.52 & 0.15 & 28.9 & 21.2 & -1 & -1 \\ 135 & 1.14 & 0.16 & 27.2 & 67.5 & -1 & -1 \\ 136 & 0.54 & 0.37 & 38.2 & 90.0 & 150 & 155 \\ 137 & 1.17 & 0.22 & 54.2 & 159.9 & 154 & 153 \\ 138 & 1.25 & 0.22 & 67.5 & 145.8 & 148 & 147 \\ 139 & 0.70 & 0.51 & 35.4 & 78.1 & 149 & 158 \\ 140 & 0.37 & 0.30 & 13.7 & 71.9 & 151 & 152 \\ 141 & 1.92 & 0.17 & 12.9 & 99.5 & -1 & -1 \\ 142 & 0.53 & 0.18 & 81.3 & 85.0 & -1 & -1 \\ 143 & 0.65 & 0.66 & 32.5 & 78.7 & 156 & 157 \\ 144 & 0.53 & 0.21 & 15.4 & 91.6 & 159 & 160 \\ 145 & 0.79 & 0.20 & 67.4 & 56.5 & -1 & -1 \\ 146 & 1.11 & 0.16 & 41.1 & 147.9 & -1 & -1 \\ 147 & 1.30 & 0.16 & 27.5 & 118.3 & -1 & -1 \\ 148 & 1.99 & 0.18 & 41.3 & 55.5 & -1 & -1 \\ 149 & 0.93 & 0.15 & 55.0 & 41.9 & -1 & -1 \\ 150 & 1.79 & 0.17 & 24.7 & 48.1 & -1 & -1 \\ 151 & 2.72 & 0.21 & 31.1 & 90.9 & -1 & -1 \\ 152 & 0.40 & 0.17 & 48.9 & 145.1 & -1 & -1 \\ 153 & 0.56 & 0.17 & 37.1 & 134.3 & -1 & -1 \\ 154 & 1.42 & 0.31 & 24.2 & 105.0 & 161 & 165 \\ 155 & 1.84 & 0.18 & 24.1 & 56.3 & -1 & -1 \\ 156 & 1.15 & 0.62 & 33.7 & 106.5 & 163 & 164 \\ 157 & 0.70 & 0.48 & 40.6 & 108.4 & 166 & 162 \\ 158 & 1.65 & 0.18 & 27.3 & 98.6 & -1 & -1 \\ 159 & 1.47 & 0.19 & 30.8 & 61.1 & -1 & -1 \\ 160 & 1.49 & 0.15 & 26.0 & 86.4 & -1 & -1 \\ 161 & 1.70 & 0.39 & 34.3 & 91.6 & 169 & 170 \\ 162 & 2.44 & 0.25 & 46.1 & 91.5 & 167 & 171 \\ 163 & 0.69 & 0.63 & 31.4 & 114.7 & 168 & 172 \\ 164 & 1.39 & 0.19 & 18.5 & 112.3 & -1 & -1 \\ 165 & 3.21 & 0.22 & 10.6 & 111.2 & -1 & -1\end{array}$




$\begin{array}{llllccc}166 & 0.44 & 0.18 & 53.1 & 43.7 & -1 & -1 \\ 167 & 1.09 & 0.28 & 47.4 & 160.8 & 174 & 173 \\ 168 & 0.98 & 0.19 & 50.5 & 53.4 & -1 & -1 \\ 169 & 0.95 & 0.32 & 34.9 & 111.8 & 175 & 176 \\ 170 & 1.79 & 0.18 & 12.2 & 96.7 & -1 & -1 \\ 171 & 0.85 & 0.55 & 42.0 & 78.0 & 177 & 178 \\ 172 & 0.81 & 0.19 & 43.7 & 119.6 & -1 & -1 \\ 173 & 0.85 & 0.19 & 22.8 & 152.6 & -1 & -1 \\ 174 & 1.28 & 0.16 & 21.1 & 118.9 & -1 & -1 \\ 175 & 1.87 & 0.19 & 36.0 & 92.6 & -1 & -1 \\ 176 & 1.53 & 0.15 & 37.1 & 54.8 & -1 & -1 \\ 177 & 0.61 & 0.51 & 38.4 & 116.2 & 179 & 180 \\ 178 & 1.12 & 0.31 & 41.3 & 100.6 & 182 & 183 \\ 179 & 1.54 & 0.33 & 40.2 & 90.4 & 184 & 181 \\ 180 & 2.41 & 0.23 & 27.6 & 96.4 & 185 & 186 \\ 181 & 0.45 & 0.13 & 74.4 & 154.7 & -1 & -1 \\ 182 & 2.51 & 0.20 & 16.4 & 100.1 & -1 & -1 \\ 183 & 1.54 & 0.17 & 30.4 & 67.2 & -1 & -1 \\ 184 & 0.24 & 0.11 & 49.4 & 105.9 & -1 & -1 \\ 185 & 0.74 & 0.15 & 35.0 & 78.7 & -1 & -1\end{array}$


Table III. Airway parameters of the symmetric subtree including a 3-generation TB subtree and a 7-generation A tree.

$\begin{array}{cccccc}\begin{array}{c}\text { Generation } \\ \text { number }\end{array} & \text { Length } & \text { Diameter } & \begin{array}{c}\text { Alveoli vol. } \\ \text { per duct } \\ 3\end{array} & \begin{array}{c}\text { Branching } \\ \text { angle }\end{array} & \begin{array}{c}\text { Gravity } \\ \text { angle }\end{array} \\ 1 & \mathrm{~cm} & \mathrm{~cm} & \mathrm{~cm} & & \\ 2 & 0.269 & 0.115 & 0 & 58.9 & 68.21 \\ 3 & 0.264 & 0.115 & 0 & 59.0 & 65.48 \\ 4 & 0.260 & 0.115 & 0 & 59.1 & 62.76 \\ 5 & 0.216 & 0.189 & 0.001066788 & 45.0 & 38.24 \\ 6 & 0.459 & 0.175 & 0.006485338 & 45.0 & 38.24 \\ 7 & 0.389 & 0.164 & 0.004848838 & 45.0 & 38.24 \\ 8 & 0.326 & 0.157 & 0.003726575 & 45.0 & 38.24 \\ 9 & 0.275 & 0.150 & 0.002869734 & 45.0 & 38.24 \\ 10 & 0.232 & 0.143 & 0.002199006 & 45.0 & 38.24 \\ & 0.196 & 0.143 & 0.002199006 & 45.0 & 38.24\end{array}$


Table IV. Relationships of lung and breathing parameters with body weight of pigs.

Dependent variable, $Y$

Model

$\mathrm{R}^{2}$

Breathing Frequency
Minute Volume $(L)$

$\mathrm{Y}=53.5 \times(\text { Body Weight in } \mathrm{kg})^{-0.26}$

0.828

Tidal Volume $(\mathrm{mL})$

$\mathrm{Y}=0.499 \times(\text { Body Weight in kg })^{0.809}$

0.975

$\mathrm{FRC}(\mathrm{mL})$

$\mathrm{Y}=9.327 \times(\text { Body Weight in } \mathrm{kg})^{1.059}$

$\operatorname{TLC}(\mathrm{mL})$

$\mathrm{Y}=24.1 \times(\text { Body Weight in } \mathrm{kg})^{1.13}$

0.941

$\mathrm{Y}=39.43 \times(\text { Body Weight in kg })^{1.06} \quad 0.960$

$\mathrm{FRC/TLC}$

$\mathrm{Y}=0.6112097 \times(\text { Body Weight in } \mathrm{kg})^{0.07}$

Alveolar Surface Area $\left(\mathrm{cm}^{2}\right)$

$\mathrm{Y}=37.325 \times(\text { Body Weight in } \mathrm{g})^{0.95948}$

0.983

Alveolar Volume $(\mathrm{mL})$

$\mathrm{Y}=0.022337 \times(\text { Body Weight in } \mathrm{g})^{1.068}$

0.994

Millions of Alveoli

$\mathrm{Y}=16.916+0.0068833$ (Body Weight in $\mathrm{g}$ )

0.991

Alveolar Surface Area $\left(\mu \mathrm{m}^{2}\right)$

$\mathrm{Y}=1192.1 \times(\text { Body Weight in } \mathrm{g})^{0.41496}$

0.957

Alveolus Volume $\left(\mu \mathrm{m}^{3}\right)$

$\mathrm{Y}=6932.66 \times(\text { Body Weight in } \mathrm{g})^{0.56418}$

0.929 


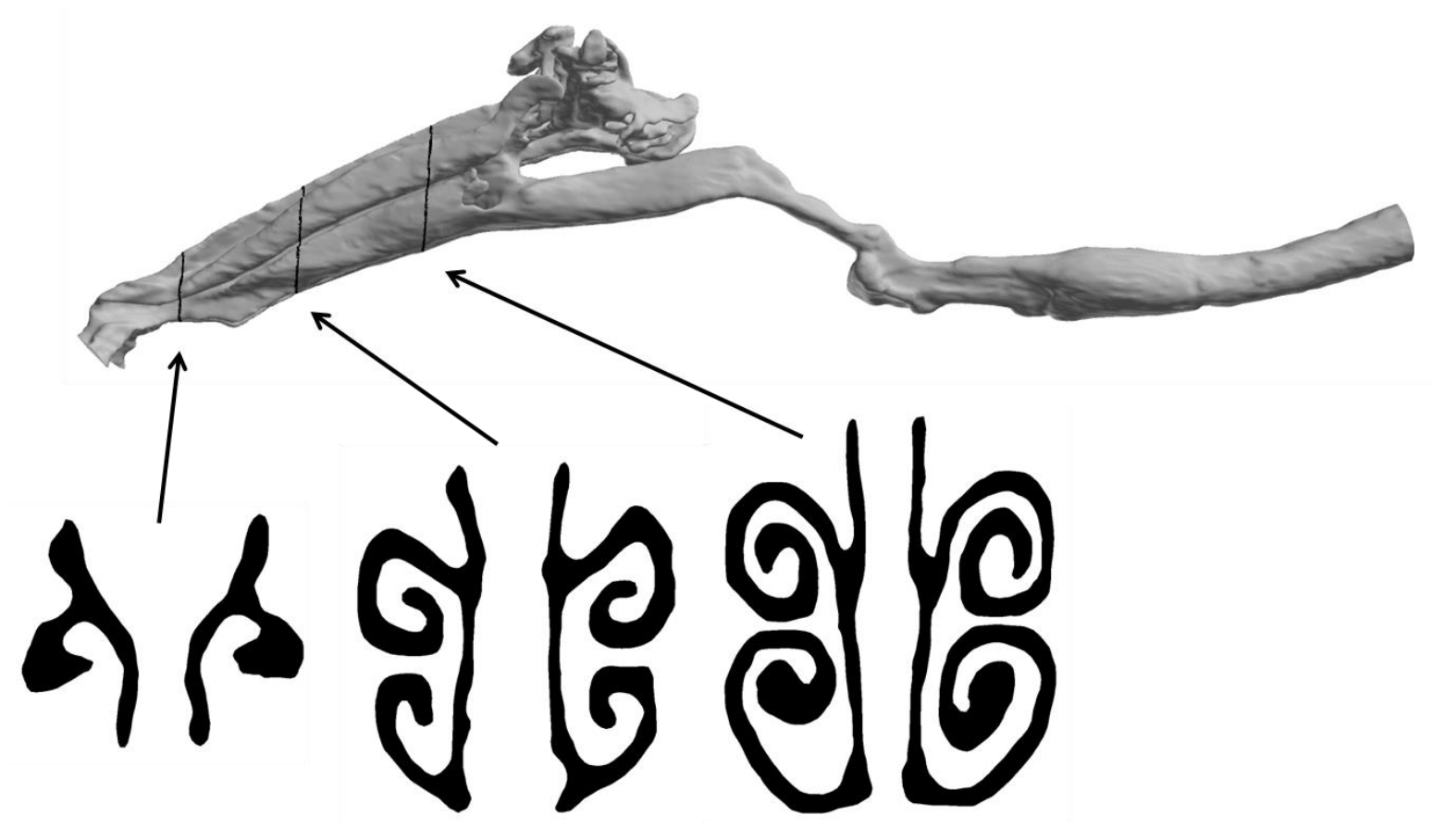

Figure 1: Lateral view of the pig URT CFD model. Three coronal cross-sections are shown in the main nasal cavity to demonstrate the airway structure. 


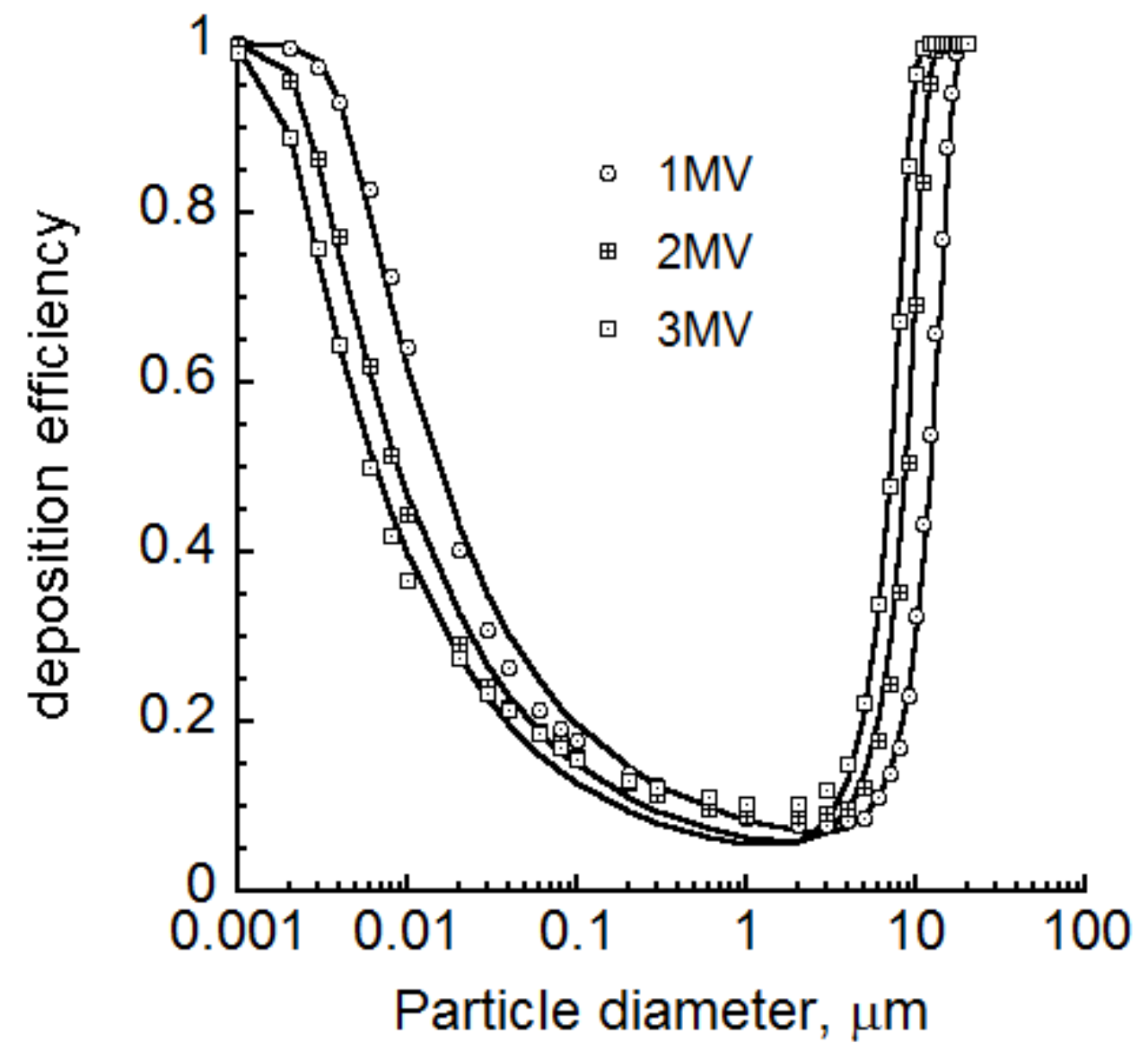

Figure 2. Comparison of numerical calculations of particle deposition fractions in the pig nasal passages indicated by circular and square markers with predictions of semi-empirical equation (1) shown by solid lines. 

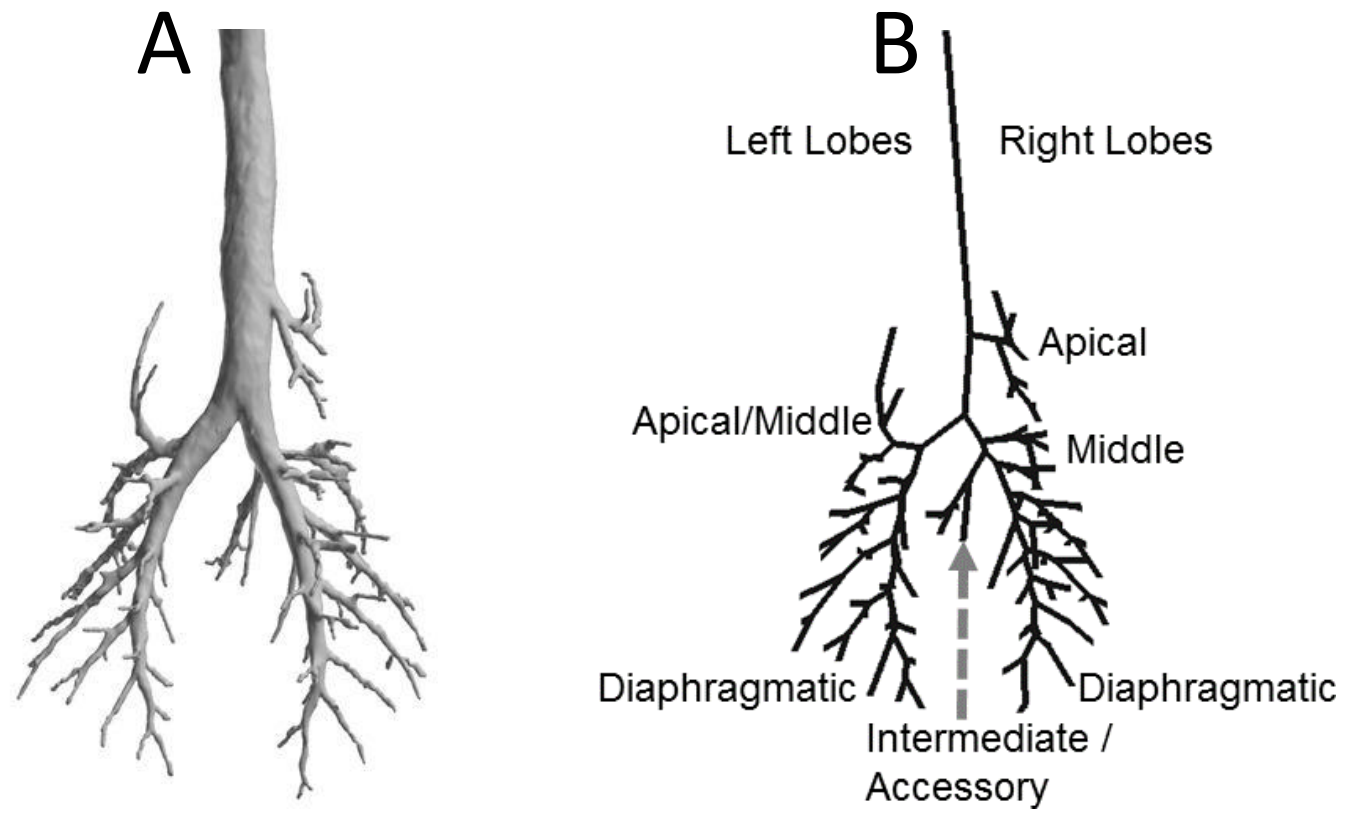

Figure 3. Monopodial airway structure of large airways of the pig TB tree from scanned images; A. Reconstructed from scanned images, B. Airways converted to cylindrical tubes. 


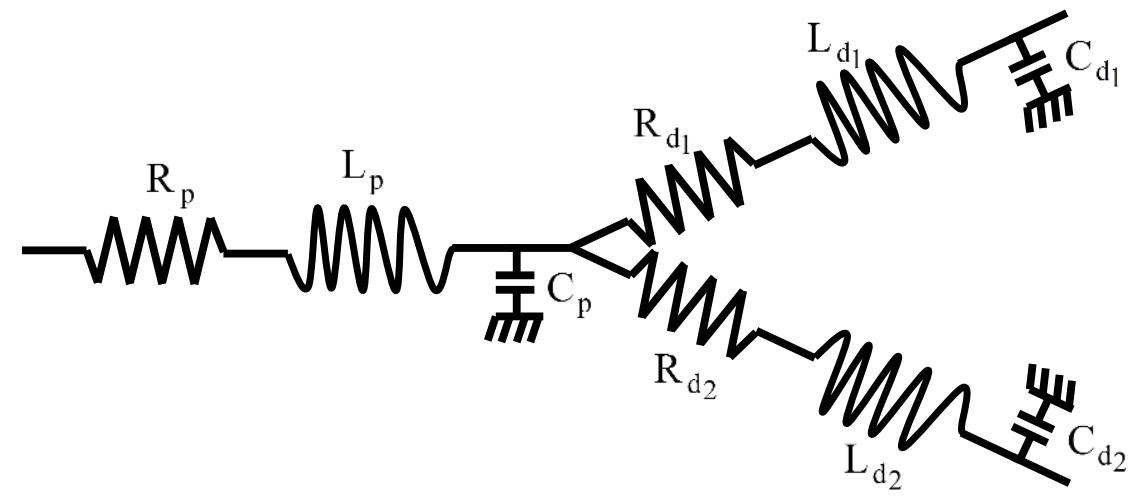

Figure 4. Electric network equivalence of an airway bifurcation where each airway is represented by a resistor, capacitor, and an inductor. 


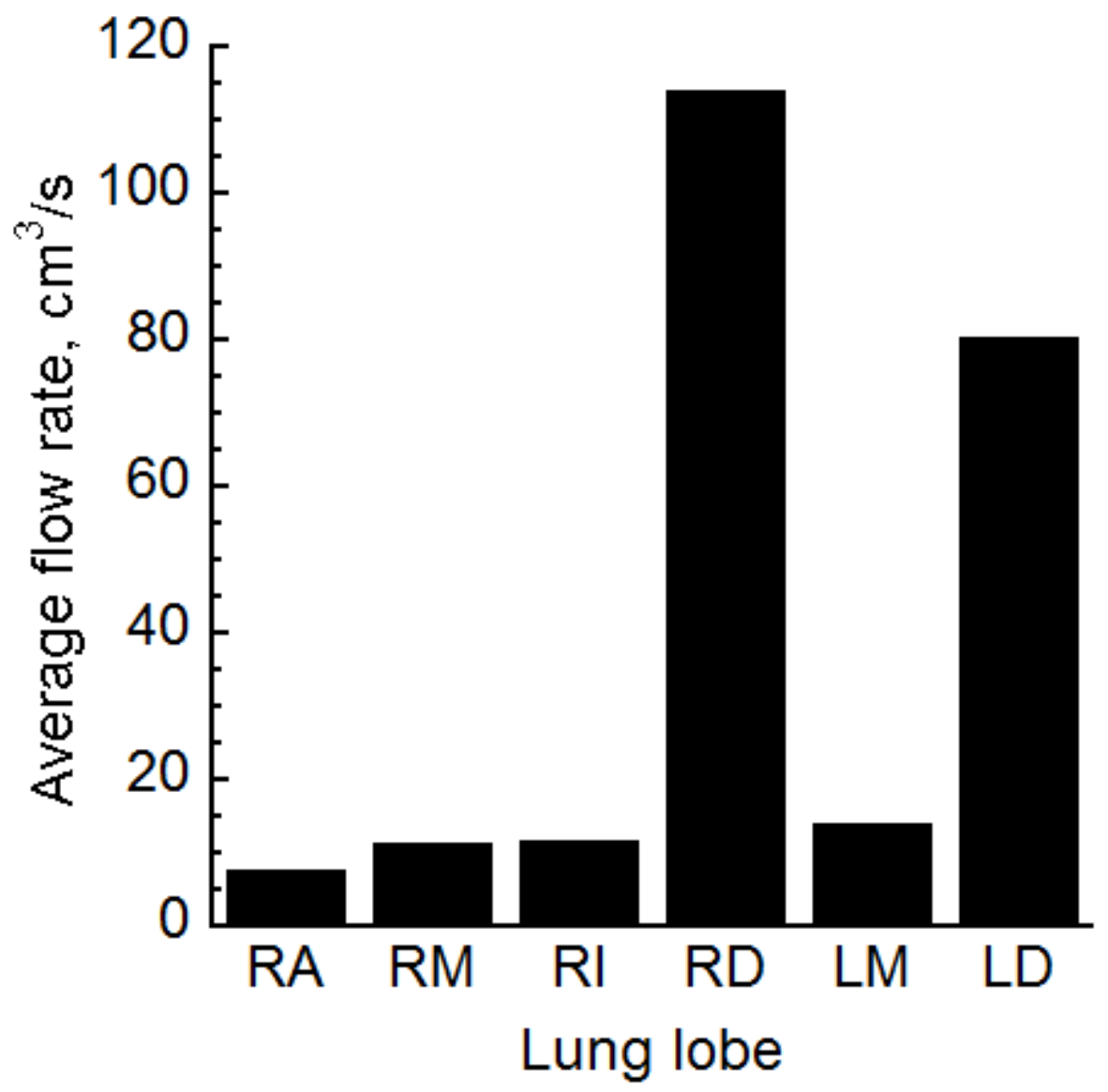

Figure 5. Average airflow rate in each lobe of the pig lung during inhalation. 

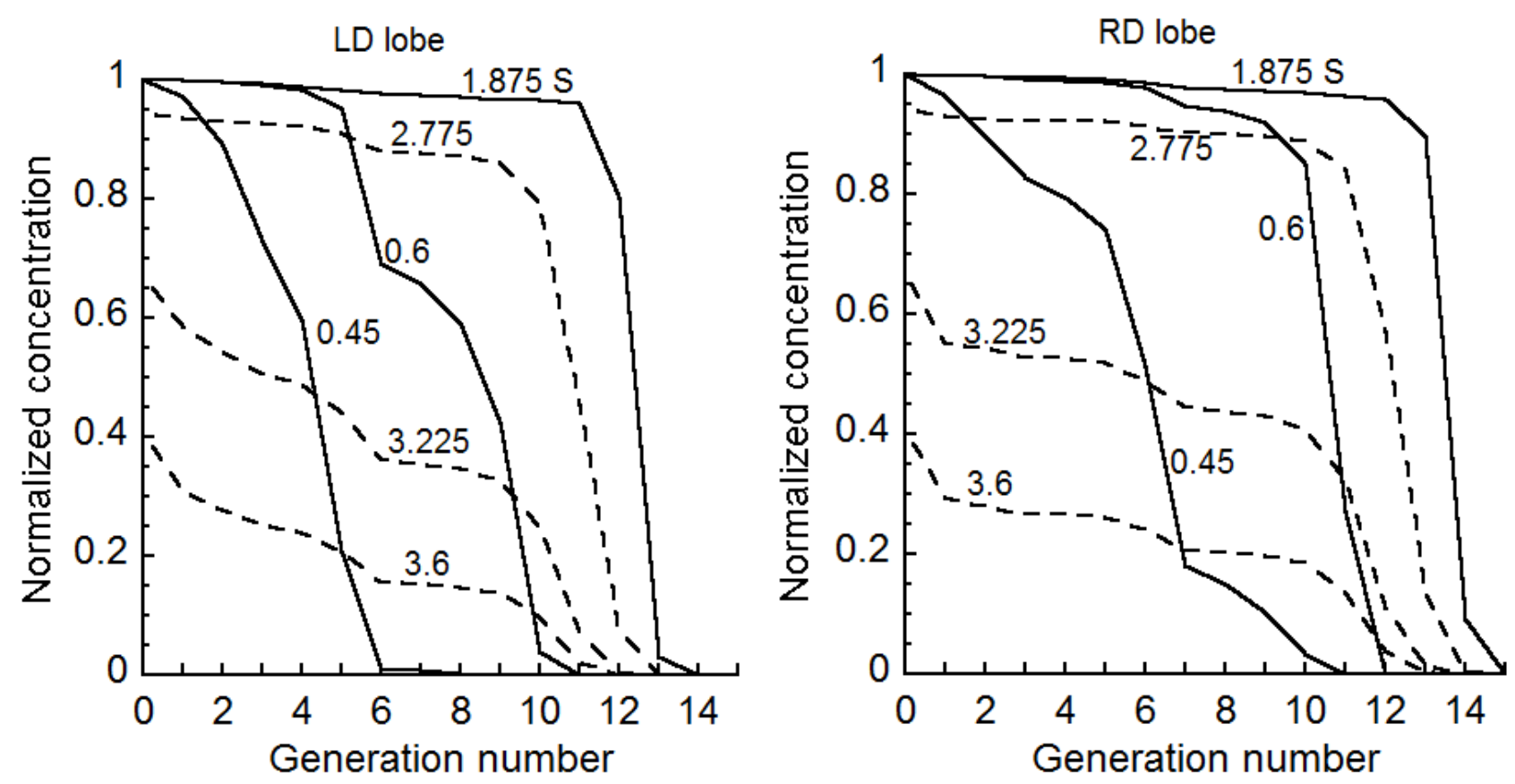

Figure 6 . Normalized concentration of $1-\mu \mathrm{m}$ particles in the left and right diaphragmatic lobes via nasal breathing. The left and right diaphragmatic lobes start at generations 5 and 6 , respectively. 


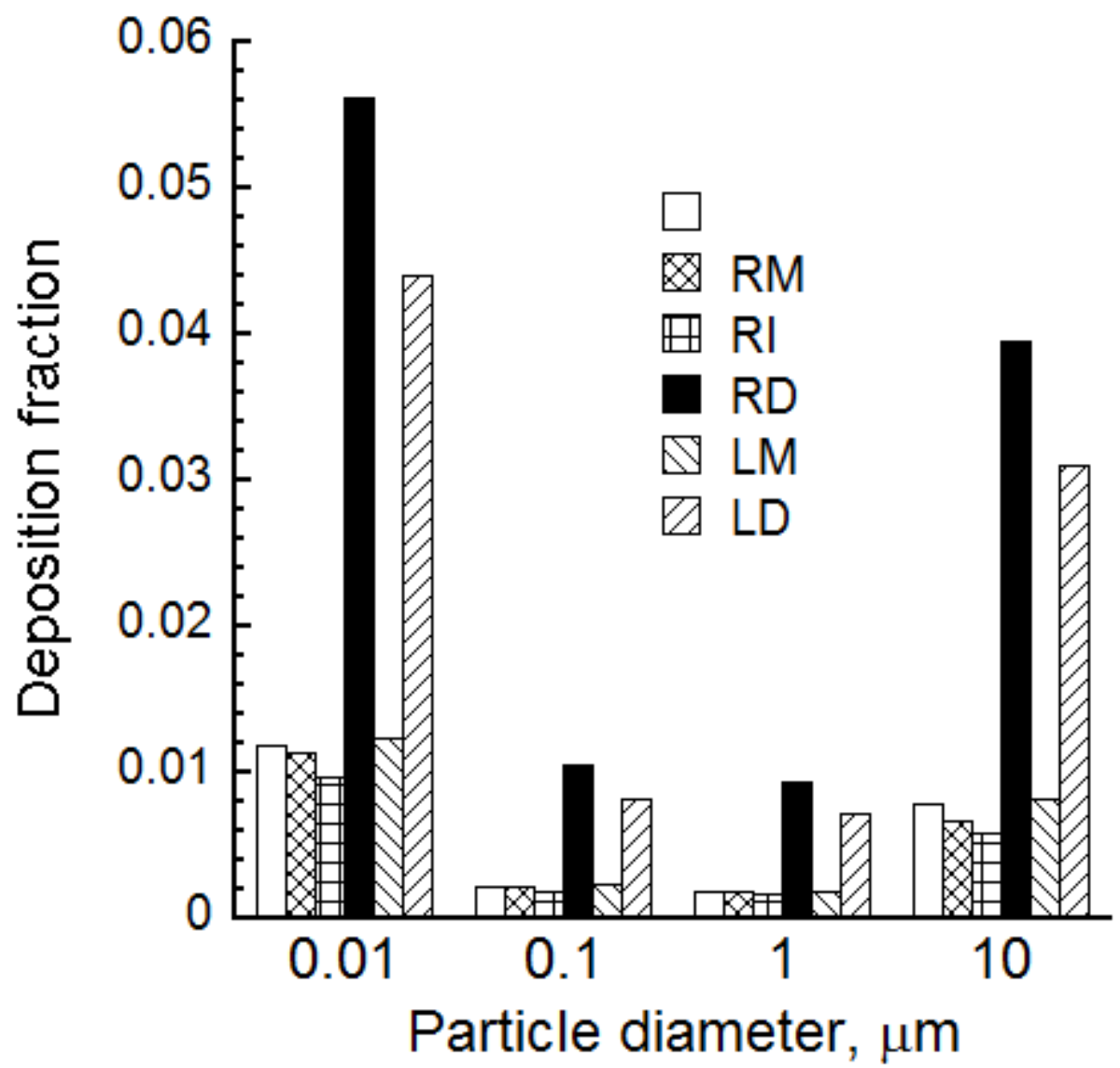

Figure 7. Deposition fraction of inhaled particles in different lobes of the pig lung via nasal breathing. 

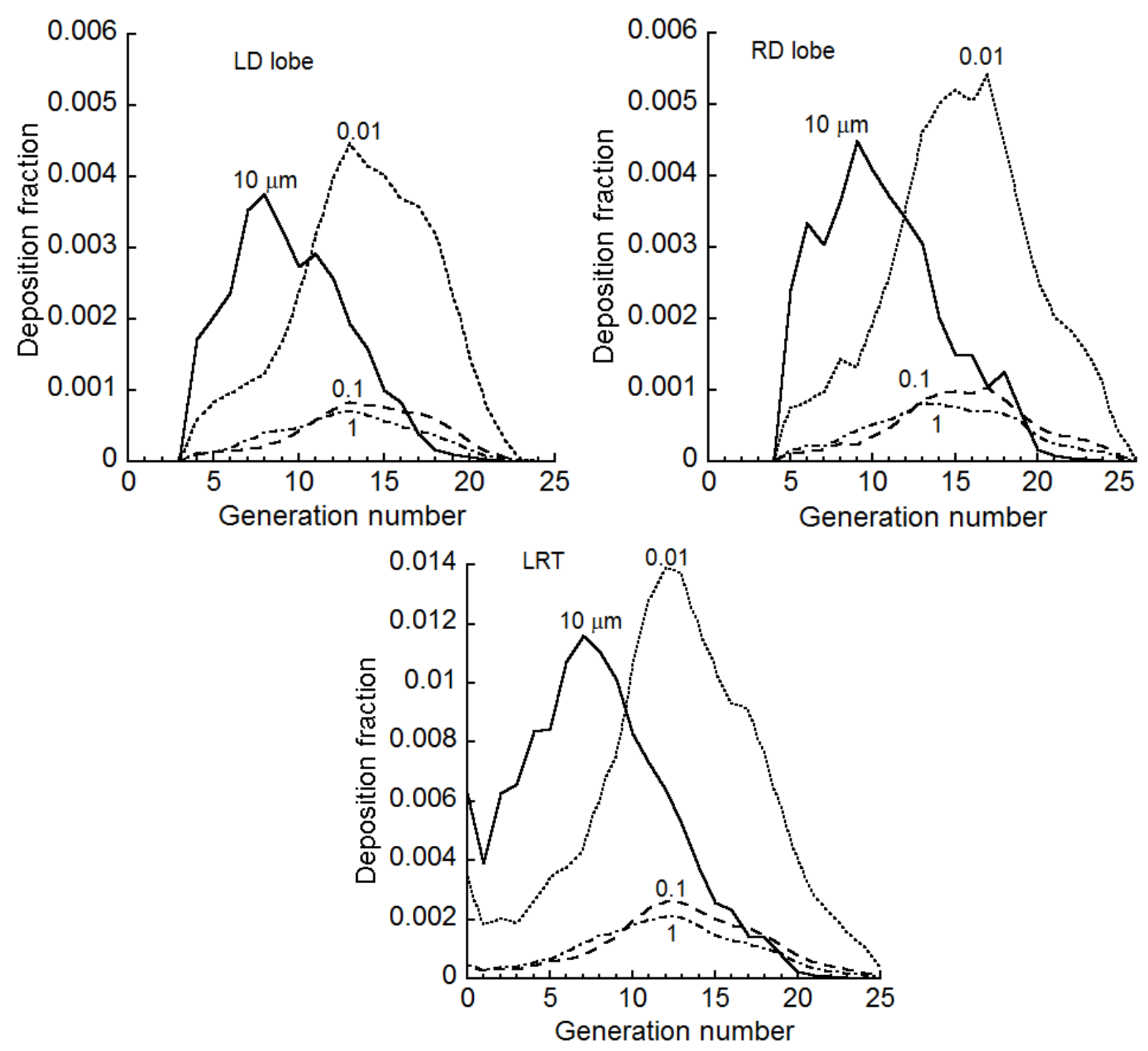

Figure 8. Deposition fraction per airway generation in the pig left and right diaphragmatic lobes and lower respiratory tract (LRT) via nasal breathing. 

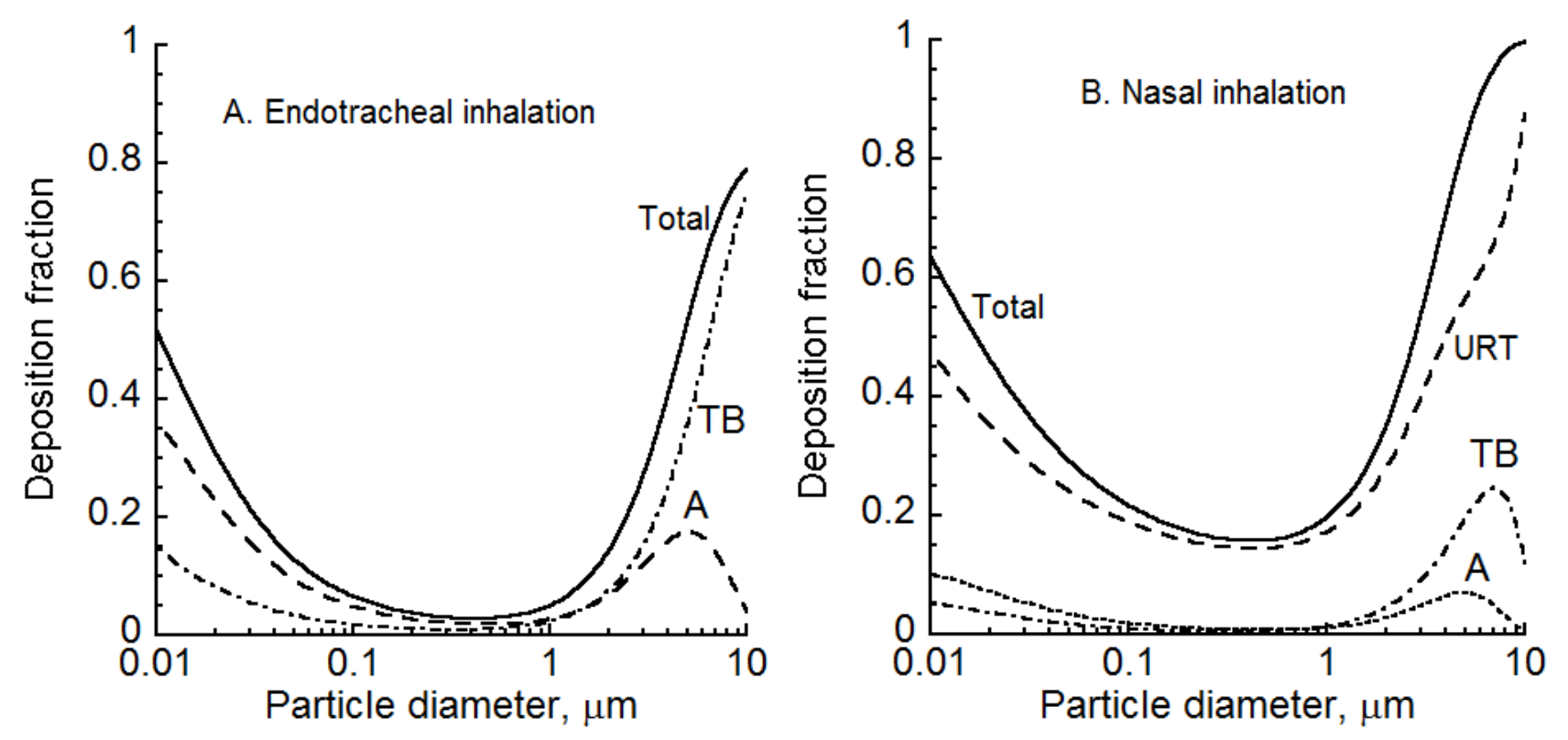

Figure 9. Deposition fractions of particles in the upper respiratory tract (URT), tracheobronchial (TB), and alveolar (A) regions and entire respiratory tract of the pig lung. 


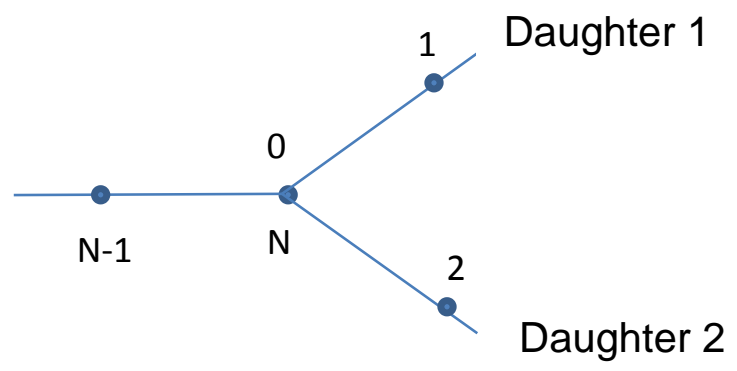

Figure A1: A bifurcation region during inhalation extending from point $\mathrm{N}-1$ in the parent airway to points 1 and 2 in daughter branches. 
Appendix A. Formulation of concentration models for exterior points.

\section{Inhalation}

Consider an airway bifurcation as shown in Figure A1 by a parent and two daughter airways. The bifurcation region is defined by the last interior point of the parent airway $(N)$ and first interior points 1 and 2 of daughter branches 1 and 2, respectively. Point 0 within the bifurcation corresponds to the last (exterior) point of the parent or starting point of daughter branches. The mass balance at the bifurcation yields

which can be rewritten as

$$
\begin{aligned}
\left.C V\right|_{t+\delta t}-\left.C V\right|_{t} & =C_{N-1} q_{p} \delta t-\left(C_{1} q_{d_{1}}+C_{2} q_{d_{2}}\right) \delta t+ \\
& \left(-D A_{p} \frac{\partial C_{N-1}}{\partial x_{p}}+D_{d_{1}} \frac{\partial C_{1}}{\partial x_{d_{1}}}+D_{A_{d_{2}}} \frac{\partial C_{2}}{\partial x_{d_{2}}}\right) \delta t-\Delta \eta q C \delta t
\end{aligned}
$$

$$
\begin{aligned}
\frac{\partial \mathrm{VC}}{\partial \mathrm{t}}= & \mathrm{C}_{\mathrm{N}-1} \mathrm{q}_{\mathrm{p}}-\mathrm{C}_{1} \mathrm{q}_{\mathrm{d}_{1}}-\mathrm{C}_{2} \mathrm{q}_{\mathrm{d}_{2}}-\mathrm{DA}_{\mathrm{p}} \frac{\partial \mathrm{C}_{\mathrm{N}-1}}{\partial \mathrm{x}_{\mathrm{N}}} \\
& +\mathrm{DA}_{\mathrm{d}_{1}} \frac{\partial \mathrm{C}_{1}}{\partial \mathrm{x}_{\mathrm{d}_{1}}}+\mathrm{DA}_{\mathrm{d}_{2}} \frac{\partial \mathrm{C}_{2}}{\partial \mathrm{x}_{\mathrm{d}_{2}}}-\Delta \eta \mathrm{qC} \delta \mathrm{t}
\end{aligned}
$$

where $\mathrm{V}$ is the volume of the bifurcation region, $\mathrm{C}$ is the particle concentration, $\mathrm{q}$, is the flow rate through the airway, $D$ is the particle diffusion coefficient, $A$ is the cross section of the airway, and $\Delta \eta$ denotes deposition fraction of particles in the bifurcation region. In addition, $x$ is the axial direction of the airway, $t$ is the elapsed time, and subscripts, $p, d_{1}, d_{2}$ and correspond to properties for the parent and first and second daughter branches, respectively. Equation (A2) is simplified into the following form for steady-state breathing.

$$
\mathrm{DA}_{\mathrm{p}} \frac{\mathrm{dC}_{\mathrm{N}-1}}{\mathrm{dx}_{\mathrm{p}}}-\mathrm{q}_{\mathrm{p}}^{\prime} \mathrm{C}_{\mathrm{N}-1}=\Omega
$$

where

and

$$
\begin{aligned}
\Omega=\mathrm{DA}_{\mathrm{d}_{1}} \frac{\mathrm{dC}_{1}}{\mathrm{dx}_{\mathrm{d}_{1}}}+\mathrm{DA}_{\mathrm{d}_{2}} \frac{\mathrm{dC}_{2}}{\mathrm{dx}_{\mathrm{d}_{2}}}-\mathrm{C}_{1} \mathrm{q}_{\mathrm{d}_{1}}-\mathrm{C}_{2} \mathrm{q}_{\mathrm{d}_{2}} \\
-\left(\mathrm{q}_{\mathrm{d}_{1}} \Delta \eta_{\mathrm{d}_{1}}+\mathrm{q}_{\mathrm{d}_{2}} \Delta \eta_{\mathrm{d}_{2}}\right) \mathrm{C}_{0}
\end{aligned}
$$

$$
\mathrm{q}_{\mathrm{p}}^{\prime}=\mathrm{q}_{\mathrm{p}}\left(1-\frac{\Delta \eta_{\mathrm{p}}}{2}\right)
$$

in which $\Delta \eta_{\mathrm{i}} \approx\left(\Delta \mathrm{x}_{\mathrm{i}} / \mathrm{L}_{\mathrm{i}}\right) \eta_{\mathrm{i}}$. Solution to (A3) - (A5) subject to inlet boundary condition of $\mathrm{C}_{\mathrm{N}-1}$ at the inlet is given by

$$
\mathrm{C}_{0}=\left(\mathrm{C}_{\mathrm{N}-1}+\frac{\Omega}{\mathrm{q}_{\mathrm{p}}^{\prime}}\right) \times \mathrm{e}^{\frac{\mathrm{q}_{\mathrm{p}}^{\prime} \Delta \mathrm{x}_{\mathrm{p}}}{\mathrm{A}_{\mathrm{p}} \mathrm{D}}}-\frac{\Omega}{\mathrm{q}_{\mathrm{p}}^{\prime}}
$$




$$
\frac{\mathrm{dC}_{0}}{\mathrm{dx}_{\mathrm{p}}}=\left(\mathrm{C}_{\mathrm{N}-1}+\frac{\Omega}{\mathrm{q}_{\mathrm{p}}^{\prime}}\right) \times \frac{\mathrm{q}_{\mathrm{p}}^{\prime}}{\mathrm{A}_{\mathrm{p}} \mathrm{D}} \times \mathrm{e}^{\frac{\mathrm{q}_{\mathrm{p}}^{\prime} \Delta \mathrm{x}_{\mathrm{p}}}{\mathrm{A}_{\mathrm{p}} \mathrm{D}}}
$$

Particle concentration for the interior point $\mathrm{N}-1$ is found from the solution of the convective diffusion equation in the parent airway. Concentrations $\mathrm{C}_{1}$ and $\mathrm{C}_{2}$ in daughter branches are needed to calculate particle concentration at the end of the parent airway or entrance to daughter branches. The steady-state convective diffusion equations for daughter branches 1 and 2 are given by

$$
\left\{\begin{array}{l}
\frac{\mathrm{d}^{2} \mathrm{C}_{\mathrm{d}_{1}}}{\mathrm{dx}_{\mathrm{d}_{1}}^{2}}-\frac{\mathrm{q}_{\mathrm{d}_{1}}}{\mathrm{~A}_{\mathrm{d}_{1}} \mathrm{D}} \frac{\mathrm{dC}_{\mathrm{d}_{1}}}{\mathrm{dx}_{\mathrm{d}_{1}}}-\frac{\Delta \eta_{\mathrm{d}_{1}}}{\Delta \mathrm{x}_{\mathrm{d}_{1}}} \frac{\mathrm{q}_{\mathrm{d}_{1}}}{\mathrm{~A}_{\mathrm{d}_{1}} \mathrm{D}} \mathrm{C}_{\mathrm{d}_{1}}=0 \\
\frac{\mathrm{d}^{2} \mathrm{C}_{\mathrm{d}_{2}}}{\mathrm{dx}_{\mathrm{d}_{2}}^{2}}-\frac{\mathrm{q}_{\mathrm{d}_{2}}}{\mathrm{~A}_{\mathrm{d}_{2}} \mathrm{D}} \frac{\mathrm{dC}_{\mathrm{d}_{2}}}{\mathrm{dx}_{\mathrm{d}_{2}}}-\frac{\Delta \eta_{\mathrm{d}_{2}}}{\Delta \mathrm{x}_{\mathrm{d}_{2}}} \frac{\mathrm{q}_{\mathrm{d}_{2}}}{\mathrm{~A}_{\mathrm{d}_{2}} \mathrm{D}} \mathrm{C}_{\mathrm{d}_{2}}=0
\end{array}\right.
$$

with boundary conditions at the end of the parent airway or entrance to daughter branches given by

$$
\left\{\begin{array}{l}
\mathrm{C}_{\mathrm{d}_{1}}=\mathrm{C}_{\mathrm{d}_{2}}=\mathrm{C}_{0} \\
\frac{\mathrm{dC}_{\mathrm{d}_{1}}}{\mathrm{dx}_{\mathrm{d}_{1}}}=\frac{\mathrm{dC}_{\mathrm{d}_{2}}}{\mathrm{dx}_{\mathrm{d}_{2}}}=\frac{\mathrm{dC}_{\mathrm{p}}}{\mathrm{dx} \mathrm{p}_{\mathrm{p}}}
\end{array}\right.
$$

By solving equations (A8) and replacing the results in equation (A7) and simplifying, the following result is obtained for particle concentration at the end of the parent airway.

$$
\mathrm{C}_{0}=\frac{\mathrm{A}_{\mathrm{p}} \mathrm{D}-\Omega_{1}}{\mathrm{~A}_{\mathrm{p}} D \mathrm{e}^{-\frac{\mathrm{q}_{\mathrm{p}}^{\prime} \Delta \mathrm{x}_{\mathrm{p}}}{\mathrm{A}_{\mathrm{p}} \mathrm{D}}}-\Omega_{1}-\Omega_{2}\left(1-\mathrm{e}^{-\frac{\mathrm{q}_{\mathrm{p}}^{\prime} \Delta \mathrm{x}_{\mathrm{p}}}{\mathrm{A}_{\mathrm{p}} \mathrm{D}}}\right) \frac{\mathrm{A}_{\mathrm{p}} \mathrm{D}}{\mathrm{q}_{\mathrm{p}}^{\prime}}} \mathrm{C}_{\mathrm{N}-1}
$$

where

$$
\begin{aligned}
& \Omega_{1}=A_{d_{1}} D \frac{\lambda_{1_{d_{1}}} e^{\lambda_{1_{d_{1}}} \Delta \mathrm{x}_{\mathrm{d}_{1}}}-\lambda_{2_{\mathrm{d}_{1}}} e^{\lambda_{2_{\mathrm{d}_{1}} \Delta \mathrm{x}_{\mathrm{d}_{1}}}}}{\lambda_{1_{\mathrm{d}_{1}}}-\lambda_{2_{\mathrm{d}_{1}}}}-\frac{\mathrm{q}_{\mathrm{d}_{1}}\left(\mathrm{e}^{\lambda_{\mathrm{d}_{1}} \Delta \mathrm{x}_{\mathrm{d}_{1}}}-\mathrm{e}^{\lambda_{2_{\mathrm{d}_{1}} \Delta \mathrm{x}_{\mathrm{d}_{1}}}}\right)}{\lambda_{1_{\mathrm{d}_{1}}}-\lambda_{2_{\mathrm{d}_{1}}}} \\
& +\mathrm{A}_{\mathrm{d}_{2}} \mathrm{D} \frac{\lambda_{\mathrm{d}_{2}} \mathrm{e}^{\lambda_{\mathrm{l}_{2}} \Delta \mathrm{x}_{\mathrm{d}_{2}}}-\lambda_{2_{\mathrm{d}_{2}}} \mathrm{e}^{\lambda_{\mathrm{d}_{2}} \Delta \mathrm{x}_{\mathrm{d}_{2}}}}{\lambda_{1_{\mathrm{d}_{2}}}-\lambda_{2_{\mathrm{d}_{2}}}}-\frac{\mathrm{q}_{\mathrm{d}_{2}}^{\prime}\left(\mathrm{e}^{\lambda_{\mathrm{d}_{2}} \Delta \mathrm{x}_{\mathrm{d}_{2}}}-\mathrm{e}^{\lambda_{2_{\mathrm{d}_{2}}} \Delta \mathrm{x}_{\mathrm{d}_{2}}}\right)}{\lambda_{1_{\mathrm{d}_{2}}}-\lambda_{2_{\mathrm{d}_{2}}}}
\end{aligned}
$$




$$
\begin{aligned}
& \Omega_{2}=\frac{\mathrm{q}_{\mathrm{d}_{1}}^{\prime}\left(\lambda_{2_{\mathrm{d}_{1}}} \mathrm{e}^{\lambda_{\mathrm{1}_{\mathrm{d}_{1}}} \Delta \mathrm{x}_{\mathrm{d}_{1}}}-\lambda_{1_{\mathrm{d}_{1}}} \mathrm{e}^{\lambda_{2_{\mathrm{d}_{1}}} \Delta \mathrm{x}_{\mathrm{d}_{1}}}\right)}{\lambda_{1_{\mathrm{d}_{1}}}-\lambda_{2_{\mathrm{d}_{1}}}}-\frac{\mathrm{A}_{\mathrm{d}_{1}} \mathrm{D} \lambda_{1_{\mathrm{d}_{1}}} \lambda_{2_{\mathrm{d}_{1}}}\left(\mathrm{e}^{\lambda_{\mathrm{d}_{1}} \Delta \mathrm{x}_{\mathrm{d}_{1}}}-\mathrm{e}^{\lambda_{2_{\mathrm{d}_{1}}} \Delta \mathrm{x}_{\mathrm{d}_{1}}}\right)}{\lambda_{1_{\mathrm{d}_{1}}}-\lambda_{2_{\mathrm{d}_{1}}}} \\
& \underline{\mathrm{q}_{\mathrm{d}_{2}}^{\prime}\left(\lambda_{2_{\mathrm{d}_{2}}} \mathrm{e}^{\lambda_{\mathrm{d}_{\mathrm{d}_{2}}} \Delta \mathrm{x}_{\mathrm{d}_{2}}}-\lambda_{1_{\mathrm{d}_{2}}} \mathrm{e}^{\lambda_{\mathrm{d}_{2}} \Delta \mathrm{x}_{\mathrm{d}_{2}}}\right)}-\mathrm{A}_{\mathrm{d}_{2}} \mathrm{D} \lambda_{1_{\mathrm{d}_{2}}} \lambda_{2_{\mathrm{d}_{2}}}\left(\mathrm{e}^{\lambda_{\mathrm{d}_{2}} \Delta \mathrm{x}_{\mathrm{d}_{2}}}-\mathrm{e}^{\lambda_{2_{\mathrm{d}_{2}}} \Delta \mathrm{x}_{\mathrm{d}_{2}}}\right) \\
& \lambda_{1_{\mathrm{d}_{2}}}-\lambda_{2_{\mathrm{d}_{2}}} \quad \lambda_{\mathrm{d}_{2}}-\lambda_{\mathrm{d}_{2}} \\
& -\left(\mathrm{q}_{\mathrm{d}_{1}} \Delta \eta_{\mathrm{d}_{1}}+\mathrm{q}_{\mathrm{d}_{2}} \Delta \eta_{\mathrm{d}_{2}}\right) \\
& \lambda_{1_{\mathrm{d}_{1}}}=\frac{1}{2} \frac{\mathrm{q}_{\mathrm{d}_{1}}}{\mathrm{~A}_{\mathrm{d}_{1}} \mathrm{D}}\left(1+\sqrt{1+\frac{4 \Delta \eta_{\mathrm{d}_{1}}}{\Delta \mathrm{x}_{\mathrm{d}_{1}}} / \frac{\mathrm{q}_{\mathrm{d}_{1}}}{\mathrm{~A}_{\mathrm{d}_{1}} \mathrm{D}}}\right) \\
& \lambda_{2_{\mathrm{d}_{1}}}=\frac{1}{2} \frac{\mathrm{q}_{\mathrm{d}_{1}}}{\mathrm{~A}_{\mathrm{d}_{1}} \mathrm{D}}\left(1-\sqrt{1+\frac{4 \Delta \eta_{\mathrm{d}_{1}}}{\Delta \mathrm{x}_{\mathrm{d}_{1}}} / \frac{\mathrm{q}_{\mathrm{d}_{1}}}{\mathrm{~A}_{\mathrm{d}_{1}} \mathrm{D}}}\right) \\
& \mathrm{q}_{\mathrm{d}_{1}}^{\prime}=\mathrm{q}_{\mathrm{d}_{1}}\left(1+\eta_{\mathrm{d}_{1}}\right) \\
& \mathrm{q}_{\mathrm{d}_{2}}^{\prime}=\mathrm{q}_{\mathrm{d}_{2}}\left(1+\eta_{\mathrm{d}_{2}}\right)
\end{aligned}
$$

It is noted that concentration at the parent daughter juncture depends on both upstream and downstream airway dimensions, airflow, and particle deposition efficiencies.

\section{Exhalation}

Modeling particle transport and deposition within an airway bifurcation during inhalation and exhalation are similar. The bifurcation region is considered to consist only of an inlet region of the parent airway of volume $\mathrm{V}_{\mathrm{p}}(\mathrm{N}$ to $\mathrm{N}-1$ in $\mathrm{A} 1)$ and fluxes of particles leaving daughter branches and entering the parent airway are known. The mass balance equation fort the bifurcation region is expressed by

$$
\begin{aligned}
\frac{\partial \mathrm{V}_{\mathrm{p}} \mathrm{C}_{\mathrm{N}-1}}{\partial \mathrm{t}}+\mathrm{C}_{\mathrm{d}_{1}} \mathrm{q}_{\mathrm{d}_{1}}+\mathrm{C}_{\mathrm{d}_{2}} \mathrm{q}_{\mathrm{d}_{2}} & -\mathrm{C}_{\mathrm{N}-1} \mathrm{q}_{\mathrm{p}}-\mathrm{DA}_{\mathrm{d}_{1}} \frac{\partial \mathrm{C}_{\mathrm{d}_{1}}}{\partial \mathrm{x}_{\mathrm{d}_{1}}} \\
& -\mathrm{DA}_{\mathrm{d}_{2}} \frac{\partial \mathrm{C}_{\mathrm{d}_{2}}}{\partial \mathrm{x}_{\mathrm{d}_{2}}}+\mathrm{DA}_{\mathrm{p}} \frac{\partial \mathrm{C}_{\mathrm{p}}}{\partial \mathrm{x}_{\mathrm{p}}}-\Delta \eta_{\mathrm{p}} \mathrm{q}_{\mathrm{p}} \mathrm{C}_{\mathrm{N}-1}=0
\end{aligned}
$$

which can be rearranged to give

where

$$
\mathrm{V}_{\mathrm{p}} \frac{\partial \mathrm{C}_{\mathrm{N}-1}}{\partial \mathrm{t}}+\mathrm{DA}_{\mathrm{p}} \frac{\partial \mathrm{C}_{\mathrm{N}-1}}{\partial \mathrm{x}_{\mathrm{p}}}-\mathrm{C}_{\mathrm{N}-1} \mathrm{q}_{\mathrm{p}}=\Omega
$$

$$
\Omega=D_{d_{1}} \frac{\partial C_{d_{1}}}{\partial x_{d_{1}}}+D_{A_{d_{2}}} \frac{\partial C_{d_{2}}}{\partial x_{d_{2}}}-C_{d_{1}} q_{d_{1}}-C_{2} q_{d_{2}}+C_{N-1} q_{p} \Delta \eta_{p}
$$

A simplifying assumption is made by which diffusion fluxes are small compared with convective fluxes at the bifurcation. Thus, equation (A19) reduces to

$$
\Omega=-\mathrm{C}_{\mathrm{d}_{1}} \mathrm{q}_{\mathrm{d}_{1}}-\mathrm{Cd}_{2} \mathrm{q}_{\mathrm{d}_{2}}+\mathrm{C}_{\mathrm{N}-1} \mathrm{q}_{\mathrm{p}} \Delta \eta_{\mathrm{p}}
$$


By equating equations (A19) and (A20), the following resulting equation is obtained for a fully developed, steady transport of particles.

$$
\mathrm{C}_{\mathrm{N}-1}=\frac{1}{1+\Delta \eta_{\mathrm{p}}}\left(\frac{\mathrm{q}_{\mathrm{d}_{1}}}{\mathrm{q}_{\mathrm{p}}} \mathrm{C}_{\mathrm{d}_{1}}+\frac{\mathrm{q}_{\mathrm{d}_{2}}}{\mathrm{q}_{\mathrm{p}}} \mathrm{C}_{\mathrm{d}_{2}}\right)
$$

